\title{
EMOTION REGULATION IN INFANTS USING MATERNAL SINGING AND SPEECH
}

\author{
by \\ Niusha Ghazban \\ Master of Arts in Psychology (M.A.), Ryerson University 2009 \\ Bachelor of Science (B.Sc.), McMaster University 2007 \\ Dissertation \\ presented to Ryerson University \\ in partial fulfillment of the \\ requirements for the degree of \\ Doctor of Philosophy \\ in the Program of \\ Psychology
}

Toronto, Ontario, Canada, 2013

CGhazban, 2013 


\section{Author's Declaration}

I hereby declare that I am the sole author of this dissertation. This is a true copy of the dissertation, including any required final revisions, as accepted by my examiners.

Niusha Ghazban (M.A., B.Sc.)

I authorize Ryerson University to lend this dissertation to other institutions or individuals for the purpose of scholarly research. I further authorize Ryerson University to reproduce this dissertation by photocopying or by other means, in total or in part, at the request of other institutions or individuals for the purpose of scholarly research. I understand that my dissertation may be made electronically available to the public.

Niusha Ghazban (M.A., B.Sc.) 


\title{
Abstract \\ EMOTION REGULATION IN INFANTS USING \\ MATERNAL SINGING AND SPEECH
}

\author{
Niusha Ghazban \\ Doctor of Philosophy in Psychology \\ Ryerson University \\ 2013
}

The interaction between a mother and her infant has been described as an intricate 'dance' involving coordinated singing and movement (Feldman, 2007). It is widely accepted that infant-directed (ID) speech, characterized as having higher pitch, slower tempo, and exaggerated intonation, is an effective means of communicating with infants and holding their attention (Papousek et al., 1985). Singing is another universally observed caregiving behaviour. Mothers across cultures intuitively use infant-directed (ID) singing to regulate their infants' emotional state (de l'Etoile, 2006; Nakata \& Trehub, 2004). While ID speech and singing appear to be equally successful in regulating infants' attention (Corbeil, et al., 2013), their effects in modulating infants' distress are less clear. More precisely, while stress and arousal are intimately connected, there is no research to date that has investigated the efficacy of speech and singing in alleviating infant distress. Using a modified version of the Face-to-Face/Still-Face (FFSF) paradigm (Tronick et al., 1978), the current study is the first to examine 10-month-old infants' behavioural and physiological responses, via Skin Conductance (SC), to their 
mother's singing and speaking. Stress was effectively induced in the still-face episode with infants exhibiting typical "still-face" behaviours and elevated SC responses. The results indicated that in the reunion episode, mother's singing was more effective in decreasing infant's physiological arousal, regulating negative affect and promoting infants' visual attention in comparison to maternal speaking. However, the genre of songs selected (e.g., play song or lullaby) might have been contributed to the positive outcomes of singing in regulating infants' emotions. Therefore, the second study used the same methodology to examine the effects of maternal play songs and lullabies on infants' physiological and behavioural responses. The results indicated that maternal play songs were more effective in regulating infants' stress as well as capturing and maintaining their attention than were soothing lullabies. Taken together, the findings indicate that maternal singing, specifically playful performances, supports infants' emotions and effectively regulates their stress. 


\section{Acknowledgements}

First and foremost I would like to express my gratitude to my advisor, Dr. Jean-Paul Boudreau for his incredible mentorship and patience throughout the years, and with this project. His enthusiasm and guidance both academically and professionally are immensely appreciated, along with his ability for fuelling my passion for developmental psychology. I am also grateful to Jean-Paul for encouraging and enabling me to become part of a network of international scholars in the world of infant studies.

I would also like to thank my supervisory committee members, Dr. Sandra Trehub for her insightful intellectual contributions and help during the preparation of this dissertation. I am also grateful to Dr. Frank Russo, for introducing me to the physiological methodologies and allowing us to shuttle babies between the CHILD and SMART Labs at Ryerson University. I would also like to thank the defense committee members, Dr. Karen Milligan, Dr. Kathleen Peets and Dr. Dale Stack for their thoughtful feedback and comments that strengthened this document.

I would like to thank my father, Reza Ghazban, for his unwavering support, wisdom and for believing in me all of my life. I am deeply indebted to my best friend and sister, Nona Ghazban, who selflessly listened and regulated my emotions long distance. This dissertation would not have been possible without the loving support of my husband Mihai Nedescu, whose profound understanding and encouragement inspired me to face the challenges. 
I am also grateful to the graduate and undergraduate students, Sabrina Aimola, Natalie Ein, and Priyanga Jeyarathnaarajah, and especially Gabe Nespoli for their hard work and invaluable assistance during data collection and coding. The support from AIRS (Advancing Interdisciplinary Research in Singing), SSHRC-MCRI is greatly appreciated. And last but not least, I would like to recognize the contributions of the many parents, and their wonderful children, who participated in my study and without whom this dissertation would not have been possible. 


\section{Dedications}

To the loving memory of my beloved mother, Zahra Hodaeian, whose legacy shapes my life to this day.

To the three pillars of my life: My Father, My Sister and My Husband, for their unconditional love, sacrifice and consistent regulation of $m y$ emotions which allowed me to pursue my goal. I cannot imagine a life without you.

To Denna and Daniel who make me laugh and bring light to my days. 


\section{Table of Contents}

Author's Declaration ................................................................ ii

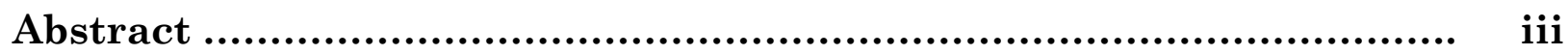

Acknowledgments ............................................................. $\quad \mathbf{v}$

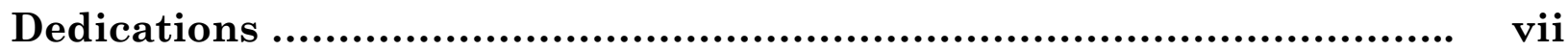

Table of Contents .............................................................. viii

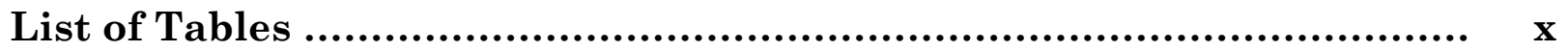

List of Figures ......................................................................... xi

List of Appendices .................................................................... xii

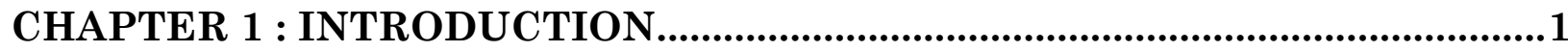

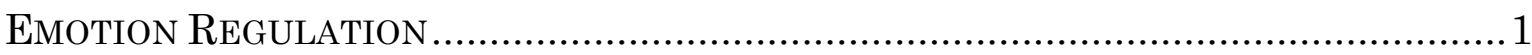

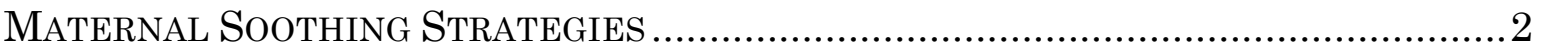

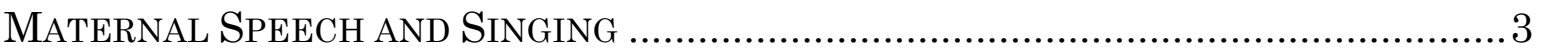

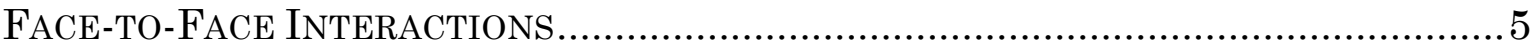

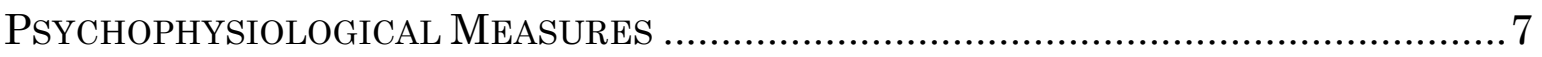

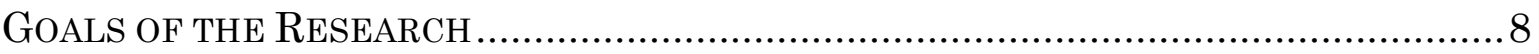

\section{CHAPTER 2 : THE EFFECT OF MATERNAL SINGING AND SPEECH ON}

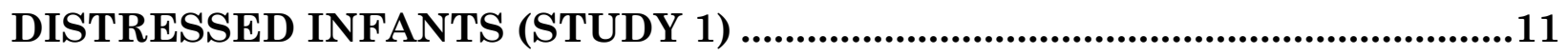

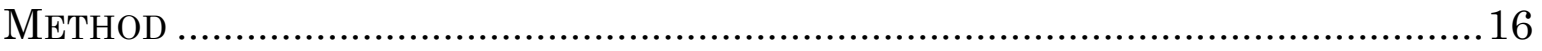

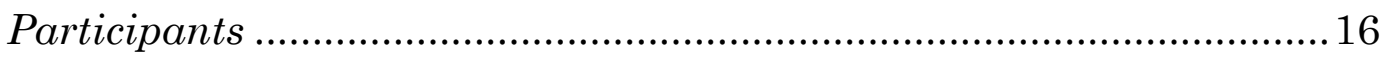

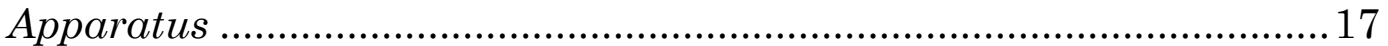

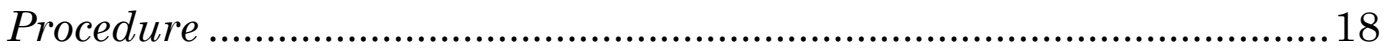

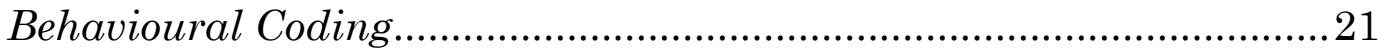

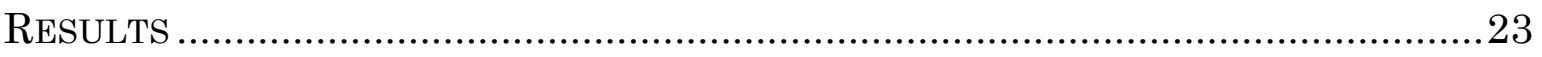

Infants' Skin Conductance Levels........................................................24

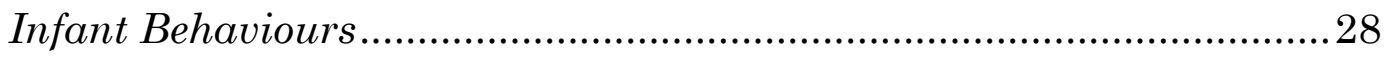

Maternal Behaviours............................................................................ 31

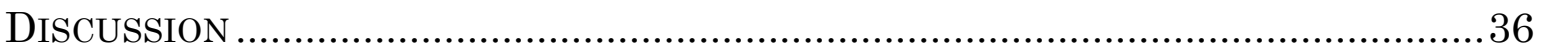




\section{CHAPTER 3 : THE EFFECT OF MATERNAL PLAY SONGS AND LULLABIES ON DISTRESSED INFANTS (STUDY 2) ....................................47}

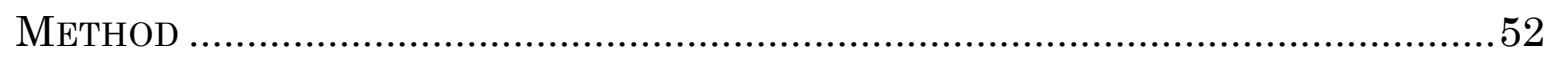

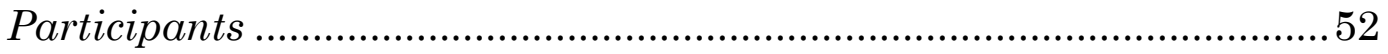

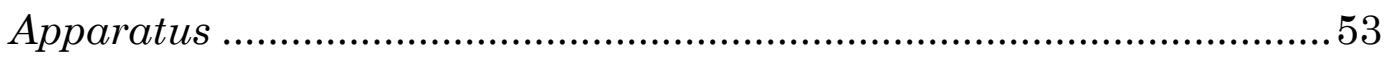

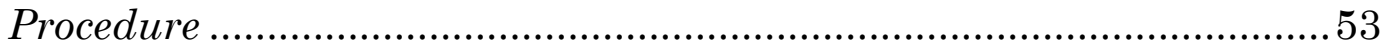

Behavioural Coding........................................................................... 55

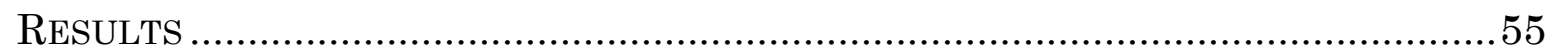

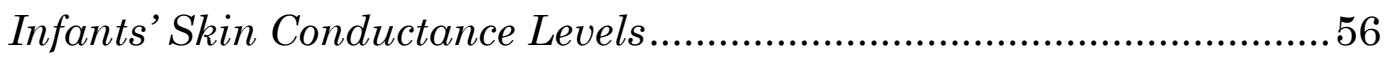

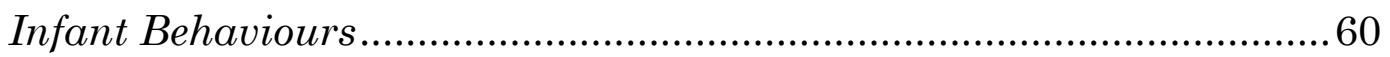

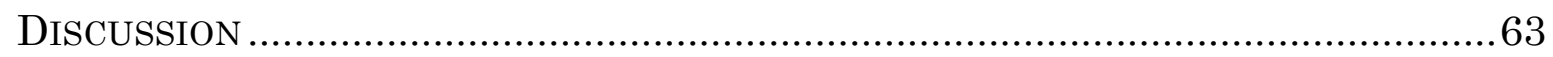

CHAPTER 4 : GENERAL DISCUSSION AND IMPLICATIONS.......................69

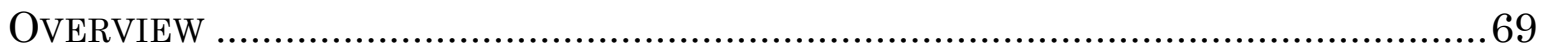

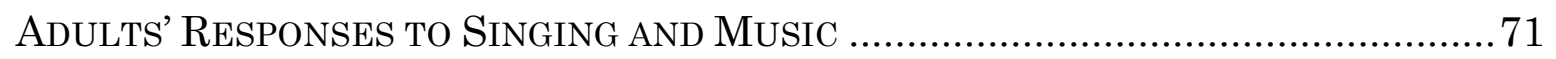

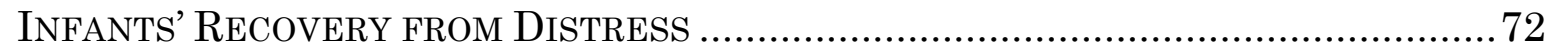

MATERnal SENSITIVITY AND INFANTS' SELF-REgULATION..................................... 75

Prosodic Features of Maternal Vocalizations .............................................. 76

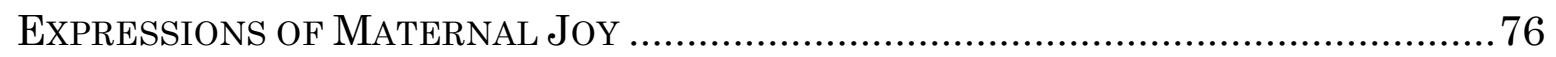

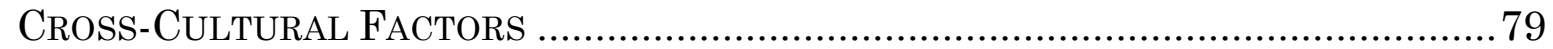

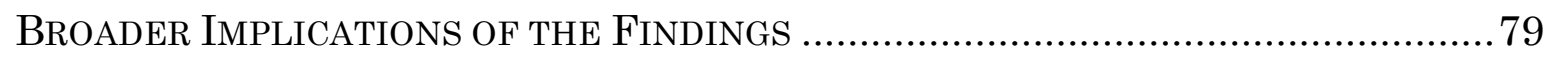

Mother-Infant Synchrony and Repairing Broken Interactions ............. 79

Maternal Vocal Interactions in Clinical Settings ................................. 80

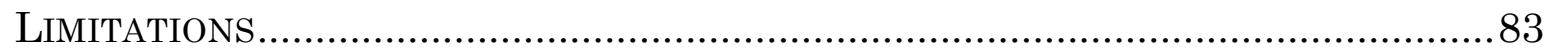

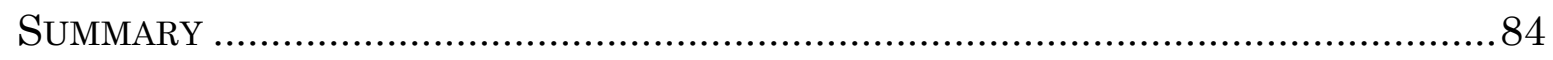

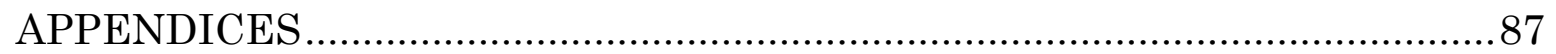

Appendix 1: Child Pre-Observations Questionnaire - Study 1 .............8 87

Appendix 2: Child Pre-Observations Questionnaire - Study 2 .............8 88

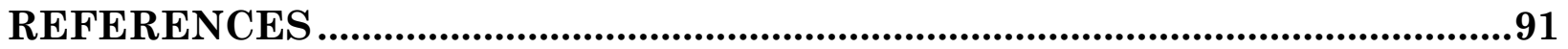




\section{List of Tables}

TABLE 1: MOTHERS' FACIAL EXPRESSIONS ACROSS THE INTERACTION EPISODE DURING

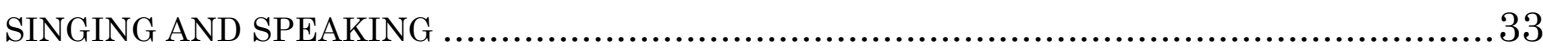




\section{List of Figures}

FIGURE 1: INFANTS' SKIN CONDUCTANCE LEVELS DURING MATERNAL SINGING AND

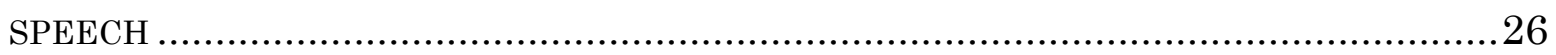

FIGURE 2: INFANTS' SKIN CONDUCTANCE LEVELS DURING FIRST EXPOSURE TO MATERNAL

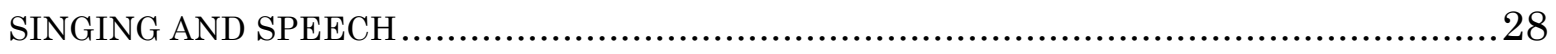

FIGURE 3: INFANTS' VISUAL FIXATION ON THE MOTHER DURING MATERNAL SINGING AND

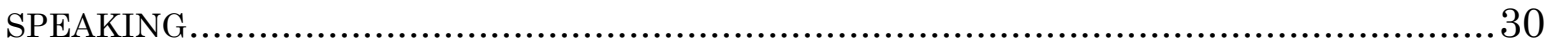

FIGURE 4: INFANTS' MINIMAL BODY MOVEMENTS ACCOMPANIED BY VISUAL FIXATION ON

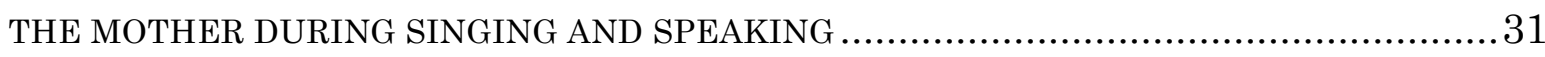

FIGURE 5: INFANTS' NEGATIVE EMOTIONAL EXPRESSIONS AND VOCALIZATIONS DURING

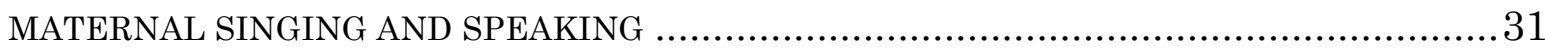

FIGURE 6: MOTHERS' EXAGGERATED FACIAL EXPRESSIONS DURING SINGING AND SPEAKING .33

FigURE 7: Mothers' HOLDING INFANTS DURING MATERNAL SINGING AND SPEAKING .... 35

Figure 8: Mothers' STROKING INFANTS DURING MATERNAL SINGING AND SPEAKING .. 36

FigURE 9: MothERS' RHYTHMICAL MOVEMENTS WITH INFANTS DURING MATERNAL SINGING AND SPEAKING

FigURE 10: INFANTS' SKIN CONDUCTANCE LEVELS DURING MATERNAL PLAY SONGS AND LULLABIES

FigURE 11: INFANTS' SKIN CONDUCTANCE LEVELS DURING FIRST EXPOSURE TO MATERNAL PLAY SONGS AND LULLABIES

FIGURE 12: INFANTS' VISUAL FIXATION ON THE MOTHER ACROSS THE REUNION EPISODE DURING MATERNAL PLAY SONGS AND LULLABIES

FIGURE 13: INFANTS' MINIMAL BODY MOVEMENTS ACCOMPANIED BY VISUAL FIXATION DURING MATERNAL PLAY SONGS AND LULLABIES

FIGURE 14: INFANTS' NEGATIVE EMOTIONAL EXPRESSIONS AND VOCALIZATIONS DURING MATERNAL PLAY SONGS AND LULLABIES 


\section{List of Appendices}

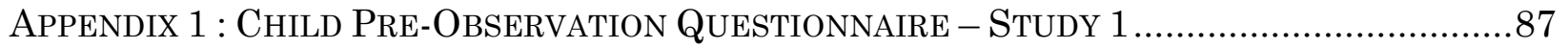

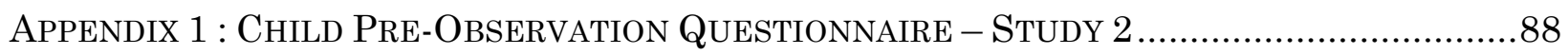




\section{CHAPTER $1:$ INTRODUCTION}

\section{Emotion Regulation}

The ability to modulate negative emotions and manage challenging situations and emotions develops rapidly in early childhood. The first detailed conceptualization of emotion regulation was provided by Claire Kopp (1989), who defined emotion regulation as "the processes and the characteristics involved in coping with heightened levels of positive and negative emotions including joy, pleasure, distress, anger, fear and other emotions" (p. 343). Kopp (1989) proposed three principles underlying self-regulation of negative emotions and distress in infants and young children. The first principle involves an action system or behavioural scheme that is implemented such as a head turn away from a distressing object or event. The second principle states that "emotion regulation is adaptive that can be innervated by different mechanisms" (p. 344). The mechanisms operate soon after birth through biologically derived tendencies, where infants use inborn reflexes for reacting to unpleasant stimuli, for example closing their eyes in response to bright lights (i.e., avoidance of physical discomfort). As infants gain experience, they are not limited to these reflexive forms of regulation and make increasing use of learned associations (e.g., cry cessation when hearing their mother prepare a bottle). After the first year of life, they capitalize on their developing cognitive resources (e.g., the ability to mentally represent, anticipate, and to evaluate different events in response to a distressing situation) and become more sophisticated in regulating their own distress. 
Kopp's (1989) third principle emphasized the critical role of caregivers' support in modulating infant emotions. Caregivers' soothing interventions are adjusted to various factors including infant age, culture, distress level, time of day, and toy availability. Thompson (1994) similarly highlights caregivers' role as external regulator and further claims that caregivers' soothing interventions provide infants with models of emotion regulation has received considerable empirical support (e.g., Feldman, 2007a; Lewis \& Ramsay, 1999).

\section{Maternal Soothing Strategies}

In the early weeks, parenting effort is devoted largely to feeding infants and facilitating their sleep. Once infants can maintain longer periods of wakefulness and alertness, caregivers engage in increasing face-to-face communication (Stern, 1974). Even during such simple social interactions, infants can reach high levels of positive and negative arousal, which provide opportunities for sensitive responses from caregivers (Feldman, 2007b). Such effective maternal emotion regulation is considered central to infants' social functioning and emotion self-regulation later in life (e.g., Kopp, 1989; Lewis \& Ramsay, 1999; Thompson, 1994).

In order to alleviate infant distress, mothers use various proximal and distal strategies, such as re-directing attention (e.g., Calkins, Gill, Johnson, \& Smith, 1999), soft vocalization (e.g., Lewis \& Ramsay, 1999), rocking (e.g., Ter Vrugt \& Pederson, 1973), picking up infants (Wolff, 1987), and touch (Stack \& Muir, 1990; Weinberg \& Tronick, 1994). Mothers use variable forms of touch to ameliorate infants' distress and regulate their emotions more generally (Jean, Stack, \& Fogel, 
2009; Jean \& Stack, 2009; Stack \& Arnold, 1998; Stack \& Muir, 1990). Infants are active participants during these interactions and engage in reciprocal touch (e.g., Moszkowski, Stack, \& Chiarella, 2009; Moszkowski \& Stack, 2007). To some extent, they can impressively regulate their own emotions in their caregiver's absence (Jean \& Stack, 2012; Lamb, Morrison, \& Malkin, 1987; Stoller \& Field, 1982; Tronick, 2005).

\section{Maternal Speech and Singing}

A mother's unique voice quality and intonation patterns are richly coded with affective meaning for infants (Fernald, 1989, 1993; M. Papoušek, Bornstein, Nuzzo, Papoušek, \& Symmes, 1990; M. Papoušek, 1994). When caregivers speak to infants, they do so with heightened pitch, exaggerated pitch contours, increased rhythmicity, and greater emotionality (Ferguson, 1978; Fernald, 1984; Nakata \& Trehub, 2004; Papousek, Bornstein, Nuzzo, Papousek, \& Symmes, 1990). This form of communication, known variously as infant-directed (ID) speech, "motherese," or "babytalk," incorporates several musical features. Fernald (1989) aptly captures this phenomenon by noting, 'the melody is the message'. According to Brandt, Gebrian, and Slevc (2012), this type of speech is a form of music. Newborns and older infants are considerably more attentive to ID speech than to adult-directed (AD) speech (Cooper \& Aslin, 1990; Fernald \& Simon, 1984; M. Papoušek, Papoušek, \& Bornstein, 1985).

Comparable ID speech modifications have been observed in a number of different languages such as German, Arabic, Spanish, Mandarin, and Japanese 
(e.g., Fernald, 1989; Grieser \& Kuhl, 1988). North American mothers tend to use more gaze during face-to-face interactions, object presentation, and ID speech to capture and maintain infants' attention (Feldman, Masalha, \& Alony, 2006; Feldman, 2007b; Maya \& Gratier, 2003). By contrast, mothers in Eastern cultures make greater use of touch, repeat more nonsense syllables, and imitate more infant vocalizations than their Western counterparts (e.g., Toda \& Fogel, 1993). More specifically, Japanese and Chinese mothers spend more time soothing their infants with soft vocalizations or touch that reflect their culture's priority for soothing infants (Grieser \& Kuhl, 1988).

Singing is another powerful and universally observed caregiving behaviour (de l'Etoile, 2006; Trehub \& Trainor, 1998). ID singing differs from non-ID singing in some of the ways that ID speech differs from AD speech (Nakata \& Trehub, 2004; Trainor, Clark, Huntley, \& Adams, 1997; Trehub, Hill, \& Kamenetsky, 1997). ID singing incorporates exaggerated rhythm, high pitch, and heightened emotionality relative to non-ID singing (Trainor \& Zacharias, 1998; Trainor, 1996). Just as infants listen more intently to ID speech than to $\mathrm{AD}$ speech, newborns and 6-monthold infants listen more attentively to ID over non-ID singing (Masataka, 1999; Trainor, 1996). At times, mothers sing gentle lullabies to soothe their infants to sleep; at other times, they sing more playful or lively songs (e.g., Rock, Trainor, \& Addison, 1999; Trehub \& Trainor, 1998). Although North Americans sing more playful than soothing songs to infants, mothers in many other cultures sing 
soothing songs regardless of the infant's state (Trehub \& Trainor, 1998; Unyk, Trehub, Trainor, \& Schellenberg, 1992).

\section{Face-to-Face Interactions}

Like maternal speech, maternal singing typically occurs in face-to-face contexts. As they advance in age, infants enjoy and depend increasingly on the reciprocal nature of social exchanges during face-to-face interactions with caregivers (DiCorcia \& Tronick, 2011; Feldman, 2006). Notwithstanding the above, infants can become over-stimulated during such interactions and exhibit distress, especially when mothers misinterpret infants' signals (DiCorcia \& Tronick, 2011; Thompson, Lewis, \& Calkins, 2008).

Infants' and caregivers' contribution to such dyadic exchanges has been studied extensively with the "Face-to-Face-Still-Face" (FFSF) Paradigm, which was first introduced by Tronick, Als, Adamson, Wise, and Brazelton (1978). In this paradigm, adult and infant sit facing one another and engage in a three-step interaction: 1) a play phase episode where the adult (usually the mother) freely interacts with her infant; 2) a 'still-face' episode in which the parent becomes unresponsive and maintains a neutral and still facial expression; and 3) a reunion episode in which the parent resumes normal interaction with the infant. The initial play period usually entails positive emotions and provides a "baseline" from which to observe behavioural and physiological aspects of dyadic interaction (Striano \& Bertin, 2004; Weinberg \& Tronick, 1996). The still-face episode confronts the infant with an unresponsive mother, often resulting in infant negative affect and 
vocalization (i.e., the still-face effect) and the need to rely on self-comfort (Weinberg $\&$ Tronick, 1996). In the reunion episode, mother and infant must repair and restore their interaction following a prolonged interactive error (i.e., the still-face). The reunion episode alone is intriguing and has received limited attention, with some infants responding to the resumption of maternal interaction with positive emotional responses (Gusella, Muir, \& Tronick, 1988) and others continuing their displays of negative responses (Adamson \& Frick, 2003; Mesman, van IJzendoorn, \& Bakermans-Kranenburg, 2009; Shapiro, Fagen, Prigot, Carroll, \& Shalan, 1998).

FFSF paradigms are being used increasingly to examine mother-infant socialization, infant self-regulation, and communication repair when the mother is suddenly unavailable to take part. Some studies have focused on the unfolding of distress over the course of the still-face episode (e.g., Fogel, Diamond, Langhorst, \& Demos, 1982; Gianino \& Tronick, 1986; Jean \& Stack, 2009; Moore \& Calkins, 2004; Stack \& Muir, 1992; Weinberg, Tronick, Cohn, \& Olson, 1999). Others have assessed mother-infant regulatory behaviours in the reunion phase (Tronick et al., 1978; Weinberg \& Tronick, 1996). Modifications of the paradigm have been aimed at learning more about infant reactivity and self-regulation, infant attention, and the effect of various maternal behaviours on infants (Cohn \& Tronick, 1988; Jean \& Stack, 2009; Murray \& Trevarthen, 1985; Stoller \& Field, 1982). Researchers are increasingly using psychophysiological measures such as salivary cortisol, vagal tone, and skin conductance to achieve greater understanding of the factors underlying infants' regulatory processes. 


\section{Psychophysiological Measures}

Threatening or emotionally distressing events result in increased salivary cortisol levels during the still-face episode (Feldman, 2007b; Haley \& Stansbury, 2003; Ham \& Tronick, 2006, 2009). Other aspects of parasympathetic activation (i.e., respiratory sinus arrhythmia [RSA]) show reductions during the still-face episode (i.e., potential indication of coping or self-regulation), and even greater reductions when parental support is provided (Calkins \& Keane, 2004; Feldman \& Eidelman, 2007; Moore \& Calkins, 2004; Moore et al., 2009).

The measurement of skin conductance (SC), also known as electrodermal activity (EDA), is determined by the number and activity of the eccrine sweat glands manifested by the sympathetic nervous system responsible for the "fight or flight” response (Eriksson, Storm, Fremming, \& Schollin, 2008; Gladman \& Chiswick, 1990; Ham \& Tronick, 2008, 2009; Storm, 2001). Emotional factors such as stress, anxiety, pain, and fear result in "emotional or mental sweating" that is most evident on the palms of the hands and soles of the feet (Storm, 2001). Such emotional sweating, which is evident by 29 weeks of gestational age provides a finer temporal resolution and responds rapidly to changes in emotion (Munsters, Wallström, Agren, Norsted, \& Sindelar, 2012; Storm, 2001). As Tronick and Ham $(2008,2009)$ note, most researchers are reluctant to use SC with infants based on "[misinformed] sentiments in the field that SC measurement is too difficult with infants ... who cannot be instructed to remain still" (p. 627). These authors highlight the importance of incorporating this measure and suggest ways of 
overcoming challenges related to movement artifact, a key rate-limiting factor in using the technique with infants.

There has been some documentation in the literature of preterm and term infants' SC responses to painful stimuli (e.g., heel pricks), non-painful tactile

stimuli (Gladman \& Chiswick, 1990; Harrison et al., 2006; Munsters et al., 2012; Storm, 2001), and loud noises (Hernes et al., 2002). SC responses have also been documented in 5-month-old infants as they interacted with a stranger who engaged in unexpected behaviour (Ham \& Tronick, 2008). Ham and Tronick (2009) also examined SC synchrony in mothers and their 5-month-old infants during the FFSF paradigm. During the still-face episode, SC levels increased and remained elevated during the reunion episode.

\section{Goals of the Research}

Infants' precocious interest in maternal speech and singing provides an opportunity to examine the role of these vocalizations in regulating the emotion of distressed infants. Much of the available research on maternal speech and singing has focused on detailed descriptions of these behaviours (Fernald \& Simon, 1984; Fernald, 1991; Nakata \& Trehub, 2004; Rock et al., 1999; Trehub \& Trainor, 1998) or their consequences for infant attention (e.g., Cooper \& Aslin, 1990; Corbeil, Trehub, \& Peretz, 2013; Fernald, 1985; Masataka, 1999; Trainor, 1996). By contrast, there has been little research on the role (or efficacy) of maternal speech or singing in modulating infant emotion or arousal (see Shenfield, Trehub, \& Nakata, 2003, for one exception) and no study has examined their effect on distressed 
infants. The present research addresses this gap in the literature by first examining the efficacy of maternal speech and singing and subsequently examining the effectiveness of each genre of singing (play songs vs. lullabies) in reducing distress in 10-month-old infants. It capitalizes on the strengths of the FFSF procedure as a controlled means of inducing distress in infants and observing mothers' success in reversing infants' distress with multimodal interactions involving speech and singing. It is hypothesized that maternal singing will be a more effective strategy in soothing fussing infants and result in reductions in their $\mathrm{SC}$ responses to levels found during the play episode in comparison to maternal speech. Moreover, infants are expected to exhibit greater visual attention and decreased negative behaviours and vocalizations in response to their mother's singing than to her speech. 



\section{CHAPTER 2 : THE EFFECT OF MATERNAL SINGING AND SPEECH ON DISTRESSED INFANTS (STUDY 1)}

Infants frequently experience transient stress from internal factors such as hunger, fatigue, and metabolic regulation, and from external factors such as unfamiliar or unexpected situations, over-stimulation or under-stimulation, and loud noise (Karraker \& Lake, 1991). Some reflexive actions such as gaze aversion and non-nutritive sucking can reduce distress to some extent in young infants (Kopp, 1989). Older infants have the potential to move away or withdraw from unpleasant stimuli and to distract themselves by changing their focus of attention to pleasant sights (Kopp, 1989; Rothbart, Ziaie, \& O’Boyle, 1992).

In general, however, infants under 2 years of age require external support to effectively disengage from emotionally arousing stimuli, and they generally receive such support from their primary caregivers (Kopp, 1989; Thompson et al., 2008). Mothers, the usual primary caregivers, are particularly influential in regulating infants' emotions through precise timing and various forms of soothing involving physical contact (e.g., Jean \& Stack, 2012), rocking (e.g., Ter Vrugt \& Pederson, 1973), distraction with objects (e.g., Harman, Rothbart, \& Posner, 1997), or vocalization (e.g., Jahromi, Putnam, \& Stifter, 2004). Communication between mother and infant is far from perfect and frequently oscillates between matched and mismatched intentions and affect (DiCorcia \& Tronick, 2011). The mother's efficacy in soothing her distressed infant is important not only for immediate 
regulation of infant affect but also for long-term self-regulation (Brazelton, Koslowski, \& Main, 1974; Kopp, 1989; Thompson, 1994).

As a part of their caregiving practices, mothers in every culture sing to their infants to maintain playful interactions or to comfort their fussy or sleepy infants (Nakata \& Trehub, 2004; Trehub et al., 1997; Trehub \& Nakata, 2002). Infantdirected (ID) singing involves exaggerated rhythm, high pitch, slow tempo, and heightened emotionality relative to non-ID versions of the same songs (Corbeil et al., 2013; Trainor et al., 1997; Trainor \& Zacharias, 1998). Newborns and 6-monthold infants show listening preferences for audio recordings of ID singing as compared with non-ID singing (Masataka, 1999; Trainor, 1996).

Mothers also alter their usual style of speech when interacting with infants (Cooper \& Aslin, 1990; Fernald, 1985; M. Papoušek et al., 1985). In comparison to adult-directed (AD) speech, ID-speech entails higher pitch, more repetition, longer pauses, slower tempo and exaggerated articulation (Fernald \& Simon, 1984; Stern, Spieker, Barnett, \& MacKain, 1983; Stern, Spieker, \& MacKain, 1982). In fact, mothers raise their pitch by about four to five semitones in playful interactions with infants (Fernald \& Simon, 1984; Papousek et al., 1985) or to capture their attention (Garnica, 1977; Stern, 1985). They use lower pitch, falling pitch contours, and less rhythmicity to soothe infants (Fernald \& Mazzie, 1991; M. Papoušek \& Papoušek, 1981). The resulting speech, which embodies many musical features, is thought to be a means of sharing maternal feelings (e.g., love, joy, tenderness) and communicating maternal intentions (Bergeson \& Trehub, 2007; Fernald, 1989). Just 
as infants listen longer to ID than to non-ID singing (Masataka, 1999; Trainor, 1996), newborns, 4-week-olds, and 4-month-old infants listen longer to audio recordings of ID speech than to adult-directed (AD) speech (Cooper \& Aslin, 1990; Fernald, 1985; Werker \& McLeod, 1989).

Maternal speech and singing are thought to be effective in regulating infant emotion or arousal (Fernald, 1991; H. Papoušek \& Papoušek, 1987), but most empirical research has focused on their efficacy in regulating infant attention. Moreover, there are few direct comparisons of their relative efficacy in gaining or maintaining infant attention. In other studies, ID singing was no more effective than talking was for engaging infants (de l'Etoile, 2006) unless it expressed more positive affect (Corbeil et al., 2013). In one study, 6-month-olds attended longer and more intensely to audio-visual recordings of maternal singing than to maternal speech (Nakata \& Trehub, 2004). In the single study that has focused on the effects of maternal singing on infant arousal, such singing modulated the salivary cortisol levels of non-distressed 6-month-olds (Shenfield et al., 2003). Although the aforementioned studies evaluated the effects of speech and/or singing on infant attention or arousal, they focused exclusively on infants who were initially content, that is, without observable distress.

The goal of the present study was to evaluate the impact of maternal speech and singing on distressed 10-month-old infants. Instead of waiting for periods of naturally occurring infant distress, we chose to elicit distress so that the distressing circumstances and their timing would be equivalent for participating infants. To 
elicit infant distress, we chose the Face-to-Face Still-Face (FFSF) Paradigm (Tronick et al., 1978), which involves the mother and infant in a three-phase, faceto-face interaction: 1) a play episode where the dyad interacts freely; 2) a 'still-face' (SF) episode, in which mother becomes unresponsive and maintains a neutral and still-facial expression; and 3) a reunion episode where mother resumes free interaction with her infant. During the first episode of free play between the dyad, infants generally exhibit decreased heart rate (i.e., evidence of attention) and increased vagal tone along with positive emotionality and engagement (Moore \& Calkins, 2004). When mothers become unresponsive in the still-face episode, infants avert their gaze, show overt signs of distress, increased skin-conductance (SC) (Ham \& Tronick, 2009), increased heart rate, and decreased vagal tone, confirming their generalized distress (Feldman \& Eidelman, 2007; Moore \& Calkins, 2004). Findings from the reunion episode have been more variable, with reports of infants' SC levels remaining elevated (Ham \& Tronick, 2009), their heart rate returning to baseline levels (Bazhenova, Stroganova, Doussard-Roosevelt, Posikera, \& Porges, 2007; Weinberg \& Tronick, 1996) or continuing to increase (Moore \& Calkins, 2004). In the reunion episode, some infants exhibit positive behaviours (Gusella, et al., 1988), but others continue to display negative emotions and seek relief from their mother with a range of "pick-me-up" gestures (Adamson \& Frick, 2003; Mesman et al., 2009; Shapiro et al., 1998). When mothers are permitted to touch infants during the still-face episode, infants exhibit more smiling and less grimacing (Stack \& Arnold, 1998; Stack \& Muir, 1990, 1992). In other stress- 
inducing situations such as inoculation or heel-prick, maternal holding and rocking has been effective at reducing infant distress (R. G. Campos, 1994; Jahromi et al., 2004). These findings indicate that infants are sensitive to maternal touch and gestures, which are often used to alleviate their distress.

The measures of interest in the present study were behavioral indicators of attention (e.g., visual fixation), distress (e.g., grimacing, negative vocalizations), and a physiological index of arousal (i.e., skin conductance). Skin conductance (SC) reflects the number and activity of the eccrine sweat glands manifested by the sympathetic nervous system (SNS), a branch of the autonomic nervous system (ANS) (Ham \& Tronick, 2008; Munsters et al., 2012; Storm, 2001). Although SC responses are unaffected by circulatory changes and responds rapidly to situations that generate fear and anxiety (Munsters et al., 2012; Storm, 2001). SC is a salient and reliable index of the SNS in comparison to other physiological measures (e.g., heart rate, vagal tone, etc.) which are an index of both SNS and parasympathetic nervous system (PNS).

For the present purposes, we followed the standard order of episodes in the FFSF paradigm but altered the timing and other details to suit the current objectives. For example, the SF episode was shorter than usual because of our interest in presenting a series of cycles with reunion episodes featuring speech or singing. Of the two studies that compared the efficacy of maternal speech and singing in maintaining infant attention (de l'Etoile, 2008; Nakata \& Trehub, 2004), only one (Nakata \& Trehub, 2004) found that maternal singing held 6-month-old 
infants' attention longer than that of maternal speech, and that study used audiovisual recording rather than live interaction. Recordings, whether audio-only or audio-visual, restrict the range of stimuli available to infants, unlike face-to-face situations in which singing and speech are usually accompanied by a variety of nonvocal cues (e.g., facial expressions, touch, movement).

It is also unclear whether the greater flexibility in the style and content of speech would offer advantages over singing in interventions with distressed infants. On the one hand, maternal speech could be empathically tuned to the momentary circumstances of infants. On the other hand, singing a well-known song could provide significant distraction from the distressing circumstances and manipulations would be restricted to expressive style.

\section{Method}

\section{Participants}

The participants were 36,10 -month-old infants ( 15 boys, 21 girls, $9.7-10.7$ months of age). Infants were excluded from the final sample because of fatigue and fussing $(n=5)$; fussing that exceeded 30 seconds in the speech condition $(n=5)$, which precluded comparisons with the singing conditions; and technical errors including mothers' occlusion of the infants' face $(n=6)$. The final sample consisted of 20 infants (mean age $=10.3$ months, 8 boys and 12 girls), were healthy, born at term, and had no family history of hearing loss. Most infants were first-born $(n=$ 18), and the ethnic composition of the families was European (59\%), African- 
American (9\%), Asian (9\%), and mixed (23\%). Mothers reported singing a variety of songs to their infants on a daily basis.

\section{$\underline{\text { Apparatus }}$}

The test room had a homogenous background of grey curtains to reduce potential distractors. Experimenters directly observed the session through a oneway mirror (located behind the infant) and discreetly provided instructions to the mother via an earphone. The interactions were recorded using two digital camcorders (Canon VIXIN) that were each focused on the infant and the parent to capture face and front of body. The recordings from the cameras were subsequently converged and synchronized using Adobe Premier for coding purposes.

Skin Conductance (SC) level (the tonic level of the electrical conductivity of skin) was measured using a Biopac MP150 (Goleta, California) system. After the application of the electrode gel paste (GEL101) to the plantar surface of the infant's right foot, two TSD203 $\mathrm{Ag}-\mathrm{AgCl}$ non-polarizable electrodes were taped to the sole of the infant's foot and secured with medical wrap to prevent the infant from tampering with the wires and to minimize movement artifact. With a $200-\mathrm{Hz}$ sampling rate, the recordings were fed into the amplifier and transmitted to an adjacent room where the data were recorded on a Macintosh computer using AcqKnowledge software, Version 4.1 (BIOPAC Systems, 2007). Throughout testing, experimenters placed stimulus markers onto the physiological recordings to mark the beginning and end of each play, still-face, and reunion episode. Physiological data were exported into MATLAB script for gain conversion and reorganized using 
the stimulus markers. Before analyzing SC data, all graphs were visually scanned for movement artifacts such as sudden large drops in SC amplitude, but none were found. It is well known from the literature that body sweat and body movements have minimal influence on the SC levels. However, it is possible that vigorous body movements (such as extreme fussing) could lead to increased SC levels. As a result, a low pass filter (i.e., $10 \mathrm{~Hz}$ ) was applied to the data which generated a similar pattern as the untransformed data. Therefore, the data was not transformed.

FeatureFinder (Andrews, Nespoli, \& Russo, 2012), a MATLAB tool, was used to visually normalize, review and segment the physiological data, and to calculate the mean changes from baseline. We segmented each trial into five time segments: the first segment consisted of the mean SC level for the last 30 seconds of the play episode as a baseline when infants were calm and content. The second segment was the mean SC level for the last 15 seconds of the still-face episode. Lastly, the reunion episode was divided into three segments and the mean SC level was calculated in 30-second intervals from the start of the reunion episode for 90 seconds (i.e., reunion I $=0-30$ s, reunion II $=30-60$ s and, reunion III $=60-90$ s). We converted the mean measures for each participant to standard $z$ scores.

\section{Procedure}

After the experimenter obtained consent, mothers completed the Child PreObservation Questionnaire (CPOQ) inquiring about infants' development and complications (see Appendix 1). One experimenter distracted the infant with soap bubbles, while another experimenter discreetly placed the electrodes on the bottom 
of the infant's foot with a medical wrap. Once the electrodes were secured, mother and infant were brought to the testing room where the infant was seated in a highchair across from mother.

Using a modified form of the Face-to-Face/Still-Face (FFSF) paradigm (Tronick et al., 1978), mother and infant engaged in a three-stage interaction: 1) face-to-face play phase, 2) mother's display of neutral still-face and, 3) the reunion phase. For the play episode, mothers were instructed to interact and use toys to play with their infants. After approximately 60 seconds, they were asked to retrieve the toys and place them in a box, out of the infant's view. Mothers were then asked to "look away" from the infant (to their left) for 5 seconds and were prompted to return to face the infant with a still, neutral facial expression for 15 seconds. During the still-face episode, mothers were required to maintain eye contact with infants but to refrain from speaking, singing, expressing emotions, or touching infants. For the reunion episode, the mother was prompted to resume social interaction with infants for 90 seconds, with vocal interactions restricted to speaking or singing. In the speaking condition, mothers were instructed to interact with their infants as they normally did at home but to refrain from singing. In the singing condition, mothers were instructed to sing songs that they usually sang at home but to refrain from speaking. Some mothers sang the same song repeatedly for the entire reunion episode, but most mothers sang various children's songs. To facilitate smooth transitions between the still-face and reunion episodes, the experimenter suggested that mothers sing their usual songs and talk about activities planned for the rest of 
the day or those that occurred the previous day. Infants experienced three repetitions of singing and speech reunion episodes for a total of six complete trials (starting with play, followed by still-face and reunion episodes) over the course of a 20-minute session. The experimenter counter balanced the conditions, where half of the mothers sang during their first reunion episode, while the others spoke. The presentation of the conditions from thereon was randomized.

The use of toys in the play phase not only minimized the interaction between the mother and infant, but pilot data revealed that infants would be reasonably content and amused themselves with toys. Toys were eliminated during the reunion phase in order to eliminate the possibility that toys would influence the results in modulating infants' arousal and distress. To reduce carry-over effects of stress from the preceding trial, play episodes were extended as needed to ensure infants were in a calm, alert state ( $n=28$ trials). Because the study's aim was to examine the effects of maternal vocalizations in regulating the emotions of distressed infants, the trials in which infants did not exhibit a physiological arousal or negative behavioural response to their mother's still-face were dropped from the final analyses ( $n=12$ trials). The play period also had to be extended on 28 trials which were generally granted towards the latter part of the experiment to allow the infant to recuperate from the repeated exposure to the still-face. If infants fretted for more than 30 seconds during the reunion or the play episodes, the session was interrupted and mothers were asked to soothe infants using toys or to pick them up if necessary. 
Once the infant was calm and mothers were in agreement, the session resumed with a new trial starting at the play episode.

\section{Behavioural Coding}

The coding of mothers' and infants' behavioural measures were conducted by different coders naïve to the study's goals. In separate passes through the digital recordings, trained coders played the files at normal speed and stopped and replayed the recording to ascertain when a particular behavioural sequence started and ended. Behavioural measures were coded as total duration within the time periods used for physiological coding (i.e., the last 30 seconds of the play episode, last 15 seconds of the still-face episode, and three 30 second intervals of the reunion episode).

Infants' behavioural responses such as visual fixation, motor activity, and negative emotional valence were coded during interactions in each of the five time segments (i.e., play episode, still-face episode, reunion I, reunion II, and reunion III). Visual fixation was defined as the duration of infant's gaze at the mother's face. Suspended motor activity was defined as the duration of suspended movements (mainly of the arms and hands) in mid-air while maintaining visual fixation on the mother's face. Negative emotional reactions included infants' negative facial expressions, grimacing, crying/fussing, sadness, frowning with lips pointing down and negative vocalizations.

The duration of four types of maternal facial expressions (negative expression, neutral expression, contented expression, exaggerated expression) during the play 
and reunion episodes were also coded. Negative expression included facial expressions of anger, irritation, sadness, and frowning with lips pointing down, while neutral expression involved neutral affect (neither positive nor negative). Contented facial expression included "warm" and inviting expression including a simple smile towards the baby, while exaggerated expression included highly dramatic facial expressions and smiling with raised eyebrows, wide eyes, and open mouth or laughing.

The duration of five types of maternal touch (e.g., embrace, holding, stroking, and rhythmical) were coded. Touch defined by embrace encompassed the mother hugging the infant, while rhythmical touch included the mother moving, bouncing or rocking the infant by the torso, arms, or hands with rhythmic regularity. Touch defined by holding consisted of a static touch that did not involve any movement while the mother's hands were on her infant. Lastly, touch defined by stroking involved the mother rubbing, massaging, or stroking her baby's face or body.

To assess inter-rater agreement, $20 \%$ of the sample was re-coded by a third trained coder who was blind to the goals of the study. Agreement was calculated if coders observed the same behaviour within 1 second of each other and quantified using kappa to correct for chance agreement. Inter-rater reliability for infants' visual fixation, suspended motor activity and negative emotional reactions were $k=$ $.94, k=.93, k=.91$ respectively. Inter-rater reliability for maternal facial expressions and touch were $k=.90 k=.91$, respectively. 


\section{Results}

Overall, mothers sang a range of songs including well-known children's songs (e.g., Itsy Bitsy Spider, Twinkle Twinkle), invented songs (e.g., original tunes that incorporated the infant's name), and ethnic songs with playful and soothing tunes. The proportion of play songs and soothing lullabies was $62 \%$ and $38 \%$, respectively. On average, mothers sang significantly more play songs $(M=2.66, S E=.21)$ than lullabies $(M=1.43, S E=.18), t(57)=-3.49, p=.001$. Infants' gender was unrelated to the physiological and behavioural measures. Furthermore, the small sample size precluded the possibility of relating socio-cultural background to style of motherinfant interactions. Therefore, these variables were collapsed and not considered in subsequent analyses. Based on previous literature (e.g., Jean \& Stack, 2009), not all infants displayed negative vocalizations, fussing and increased SC levels during the still-face episode. Because the study's aim was to examine the effects of maternal vocalizations in regulating the emotions of distressed infants, the trials in which infants did not exhibit a physiological arousal or negative behavioural response to their mother's still-face were dropped from the final analyses ( $n=12$ trials).

The 20 infants contributed 112 trials (58 singing, 54 speaking), with each infant contributing at least 2 trials to each condition. More specifically, 12 infants contributed six trials (36 singing and 36 speech trials), and 8 infants contributed five trials (22 singing and 18 speech trials). It should be noted that a decrease in SC levels is indicative of a reduction in autonomic arousal, while an increase in SC levels is indicative of increased arousal. 


\section{Infants' Skin Conductance Levels}

From Play Episode to Still-face Episode. We examined whether stress was effectively induced with the still-face paradigm in both singing and speaking conditions by means of a 2 (time segment) X 2 (condition) repeated measures ANOVA on the standardized SC values ( $z$-scores). The ANOVA revealed a significant main effect of time segment, $F(1,19)=7.01, p=.016$, indicating that infants displayed increased physiological arousal from the play episode to the stillface episode highlighting the efficacy of the stress-inducing manipulation.

Across Interaction Episodes. We examined infants' mean SC changes across play episode, still-face episode, and the three 30-second segments of the reunion phase. A 5 (time segment) X 2 (condition) repeated measures ANOVA revealed that Mauchley's test of sphericity had been violated for time segments, $\varepsilon=.513 ; X^{2}(9)=$ $54.60, p<.05$, and the interaction, $\varepsilon=.440 ; X^{2}(9)=43.02, p<.05$. Therefore, degrees of freedom were corrected using Greenhouse-Geisser estimates. The ANOVA revealed a significant main effect of time segment, $F(2.05,39.00)=14.12$, $p<.0001$, suggesting that $\mathrm{SC}$ levels increased from the play phase to subsequent phases. There was also a significant interaction between time segment and condition, $F(1.76,33.46)=6.23, p=.007$, which indicates that mother's voice had different effects on infant SC levels in different phases of the interaction. To break down the interaction, contrasts were performed between maternal singing and speaking conditions comparing all interaction episodes to the baseline or play episode. The analysis revealed a significant interaction, with infants' stress levels 
significantly lower during maternal singing $(M=.29, S E=.10)$ than during maternal speech $(M=.86, S E=.14)$ during the last reunion episode (III), $F(1,19)=$ $8.52, p=.009, r=.56$.

Across Reunion Segments. Although infant SC levels decreased during the maternal singing condition, differences between maternal singing and speaking conditions were examined further across the reunion segments. A 3 (time segment) $\mathrm{X} 2$ (condition) repeated measures ANOVA revealed a significant interaction, $F(2$, $38)=17.70, p<.0001$. Planned contrasts indicated a significant interaction between maternal singing and speaking when comparing reunion I and II, $F(1,19)=11.19$, $p<.003, r=.61$, and reunion I and III, $F(1,19)=29.33, p<.0001, r=.78$, and reunion II and III, $F(1,19)=8.56, p=.009, r=.56$. In fact, SC levels decreased significantly within 30-60 seconds into the reunion episode when mothers were singing, $F(1,19)=11.19, p=.009, r=.61$. As illustrated in Figure 1, SC levels decreased during maternal singing from reunion I $(M=.48, S E=.09)$ to reunion II $(M=.44, S E=.09)$, to reunion III $(M=.29, S E=.10)$, while mean SC levels increased during maternal speech from reunion I $(M=.48, S E=.12)$, to reunion II $(M=.75, S E=.14)$, to reunion III $(M=.86, S E=.14)$. The difference in overall SC levels during maternal singing $(M=.40, S E=.08)$ and $\operatorname{speech}(M=.70, S E=.12)$ did not reach conventional significance levels $F(1,19)=2.16, p=.158$.

Based on quadratic extrapolations of the data (see Figure 1), continued maternal singing beyond the 90 -seconds reunion duration would have resulted in SC returning to levels observed during the play episode. Comparable extrapolations 
reveal that continued speaking to infants would have resulted in increased elevation of SC levels.

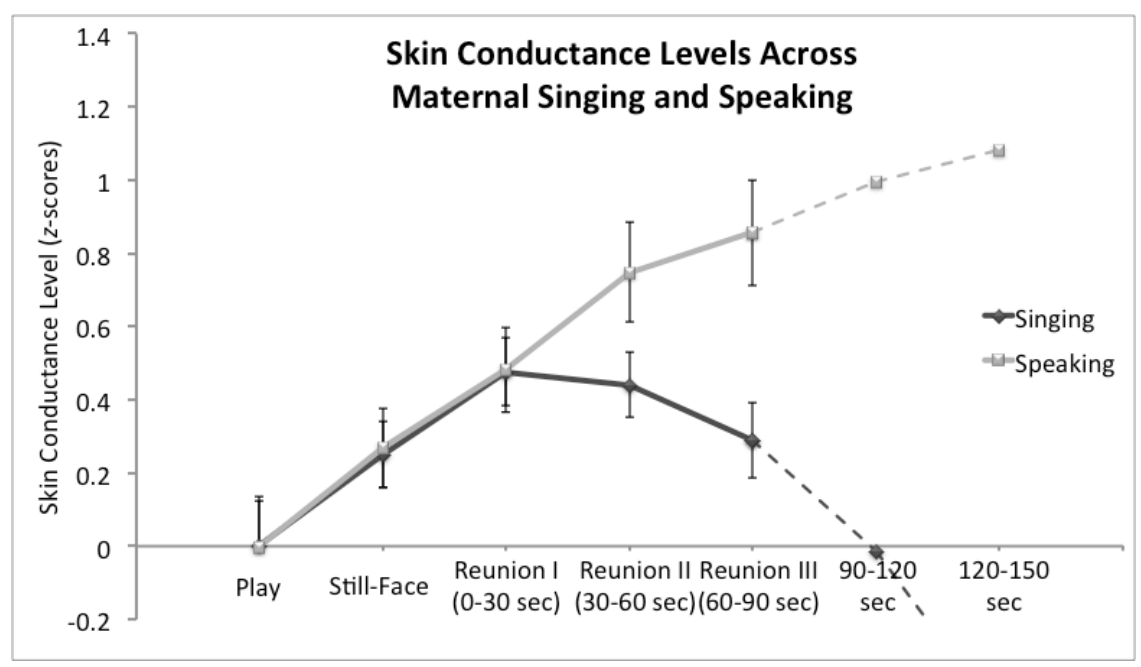

Figure 1: Infants' skin conductance levels during maternal singing and speech

First Trial with Maternal Singing or Speech. Despite precautions to ensure that infants had recovered from the previous trial before beginning the subsequent trial, repetitions of the still-face paradigm may have had cumulative effects on infant distress, with little distress evident on the very first trial. This question was examined with 24 infants $^{1}$ contributing data from their first reunion episode of singing or speaking. A 2 (time segment) X 2 (condition) repeated measures ANOVA

${ }^{1}$ The examination of infants' first exposure to maternal singing and speech resulted in more infants being included $(n=4)$ who had to be excluded from the overall analyses due to fussiness in subsequent trials. 
revealed a significant main effect of time segment, $F(1,23)=8.96, p=.006$, suggesting that stress was induced successfully on the initial trial.

SC measures were examined further during the reunion episode by means of a 3 (time segment) X 2 (condition) repeated measures ANOVA, which showed a significant interaction, $F(2,46)=13.93, p<.0001$. Planned contrasts indicated that during maternal singing, infants' SC levels decreased significantly from reunion I $(M=.45, S E=.14)$ to reunion II $(M=.36, S E=.15), F(1,23)=18.29, p<.0001, r=$ .67 , and from reunion I to reunion III $(M=.23, S E=.15), F(1,23)=18.12, p<$ $.0001, r=.66$. During maternal speech, however, SC levels increased successively from reunion I $(M=.60, S E=.19)$ to reunion II $(M=.96, S E=.20)$ to reunion III ( $M$ $=.99, S E=.19)$. The main effect of condition approached significance, with infants' overall SC level in the reunion episode being lower during maternal singing ( $M=$ $.39, S E=.14)$ than during maternal speech $(M=.85, S E=.19), F(1,23)=3.96, p=$ .059]. As illustrated in Figure 2, infants' first exposure to maternal singing and speech confirmed our previous findings that singing lowered infant SC levels within 30-60 seconds, with the largest difference observed during the last segment of the reunion. 


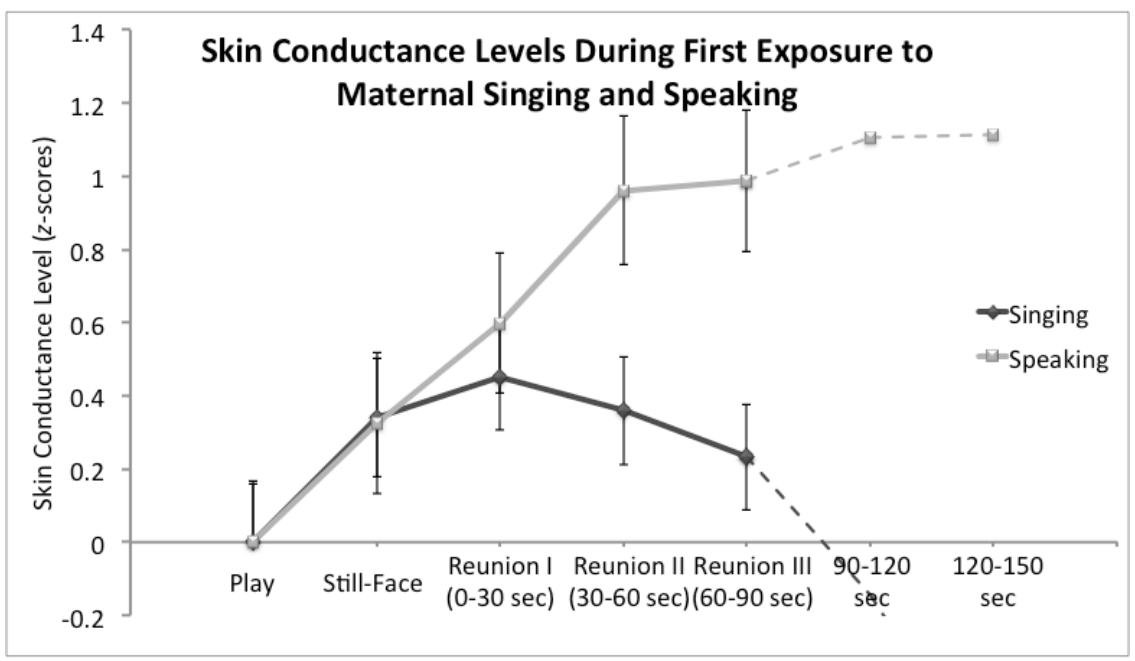

Figure 2: Infants' skin conductance levels during first exposure to maternal singing and speech

Infant Behaviours

Visual Fixation and Intensity of Engagement with Mother. Infants' attention, as indicated by fixation on the mother's face during speaking and singing conditions, was examined across the interaction episodes. A 5 (time segment) X 2 (condition) repeated measures ANOVA, with degrees of freedom corrected by means of Greenhouse-Geisser estimates of sphericity because Mauchley's test of sphericity indicated violations of sphericity for time segments, $\varepsilon=.578 ; X^{2}(14)=42.11 p<.05$, revealed a significant main effect of time segments, $F(2.32,44.02)=24.90, p<$ $.0001]$. Planned contrasts indicated that in comparison to the play phase $(M=1.88 \mathrm{~s}$, $S E=.36$ ), infants were more likely to look at their mother during the reunion episodes $[M($ reunion $I)=8.01 \mathrm{~s}, S E=.88 ; M($ reunion $I I)=8.24 \mathrm{~s}, S E=1.04 ; M$ (reunion $I I I)=8.38 \mathrm{~s}, S E=1.01]$. This result is not surprising in light of their engagement with toys during the play episode. However, there were no significant differences in visual fixation between the play episode and the still-face $(M=2.93 \mathrm{~s}$, $S E=.66), F(1,19)=1.78, p=.198$. Consistent with previous findings (e.g., Mesmen 
et al., 2009), infants increased their visual fixation from the still-face episode to reunion I $[F(1,19)=44.42, p<.0001, r=.84]$, from still-face to reunion II $[F(1,19)$ $=32.80, p<.0001, r=.80]$, and from still-face to reunion III $[F(1,19)=31.38, p<$ $.0001, r=.80]$. There was also a significant interaction between the time segments and conditions indicating that infants were more likely to look at their mother during the singing condition when comparing the still-face episode to reunions I, II, and III. Additional analysis of infants' gaze during the play episode indicated that infants looked longer at the toys $(M=26.62 \mathrm{~s}, S E=.66)$ than at their mother's face $(M=2.93 \mathrm{~s}, S E=.66) F(1,19)=327.75, p<.01$, in line with expectations.

We further examined infant looking time across the reunion episode using a 3 (time segment) X 2 (condition) repeated measures ANOVA and found a significant main effect of condition on visual fixation across the reunion episode, $F(1,19)=$ $17.50, p<.0001$. Cumulative fixation during maternal singing $(M=31.75 \mathrm{~s}, S E=$ 1.30) was significantly greater than that during maternal speech $(M=17.63 \mathrm{~s}, S E=$ .78) (see Figure 3). Another 3 (time segment) X 2 (condition) repeated measures ANOVA found that infants also displayed greater cumulative fixation accompanied by minimal body movement, an index of intense attention (Nakata \& Trehub, 2004) during maternal singing $(M=19.92 \mathrm{~s}, S E=1.24)$ than during maternal $\operatorname{speech}(M=$ $4.99 \mathrm{~s}, S E=.33), F(1,19)=14.98, p<.0001]($ see Figure 4$)$.

Negative Affect during Reunion Segments. An examination of negative affect, which included negative facial expression and vocalizations by means of a 2 (time segment) X 2 (condition) analysis revealed that infants exhibited more negative 
affect during still-face $[M=7.62 \mathrm{~s}, S E=.90]$ than play episodes $(M=.44 \mathrm{~s}, S E=.21$; $F(1,19)=75.88, p<.01)$, in line with the SC changes. A 3 (time segment) X 2 (condition) repeated measures ANOVA revealed a significant interaction of condition and time segment, $F(2,38)=3.84, p=.034$. Planned contrasts revealed that during maternal speech, infants exhibited more negative affect during reunion II $(M=15.66 \mathrm{~s}, S E=2.20)$ than reunion III $(M=10.62 \mathrm{~s}, S E=1.53), F(1,19)=4.81$, $p=.041, r=.45]$, or reunion I $(M=13.66 \mathrm{~s}, S E=1.85), F(1,19)=6.03, p=.024, r=$ .41]. These results appear to indicate that infants are more likely to protest and become upset during maternal speech interactions halfway into the reunion, eventually displaying less crying and fussiness in the last part of the reunion (see Figure 5).

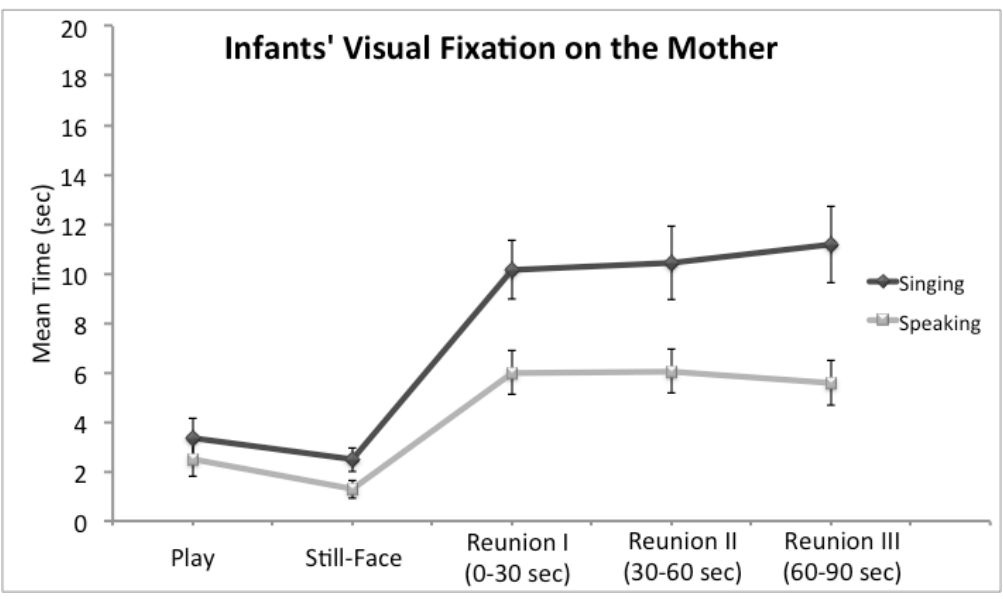

Figure 3: Infants' visual fixation on the mother during maternal singing and speaking 


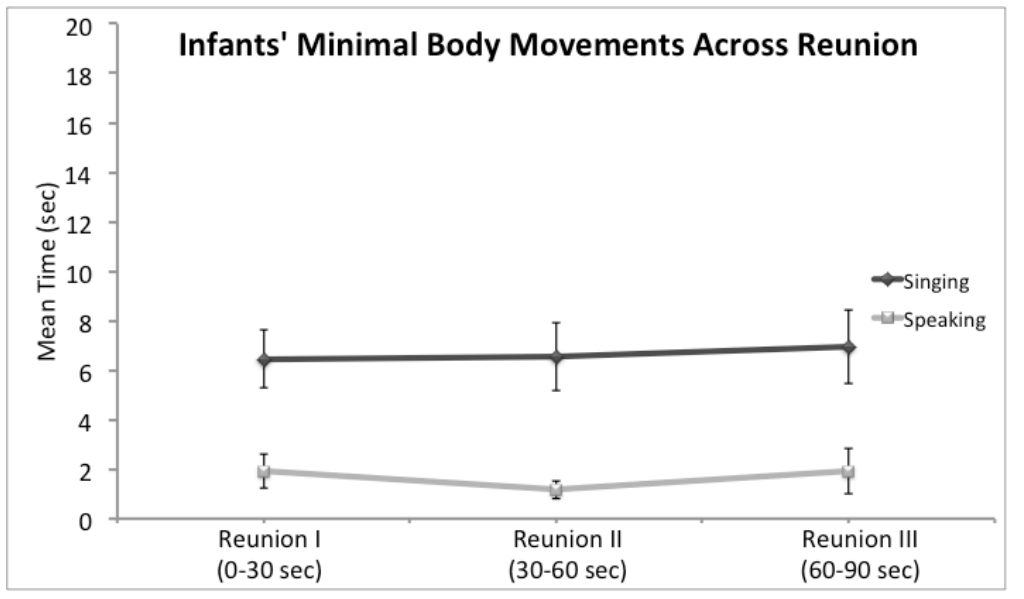

Figure 4: Infants' minimal body movements accompanied by visual fixation on the mother during singing and speaking

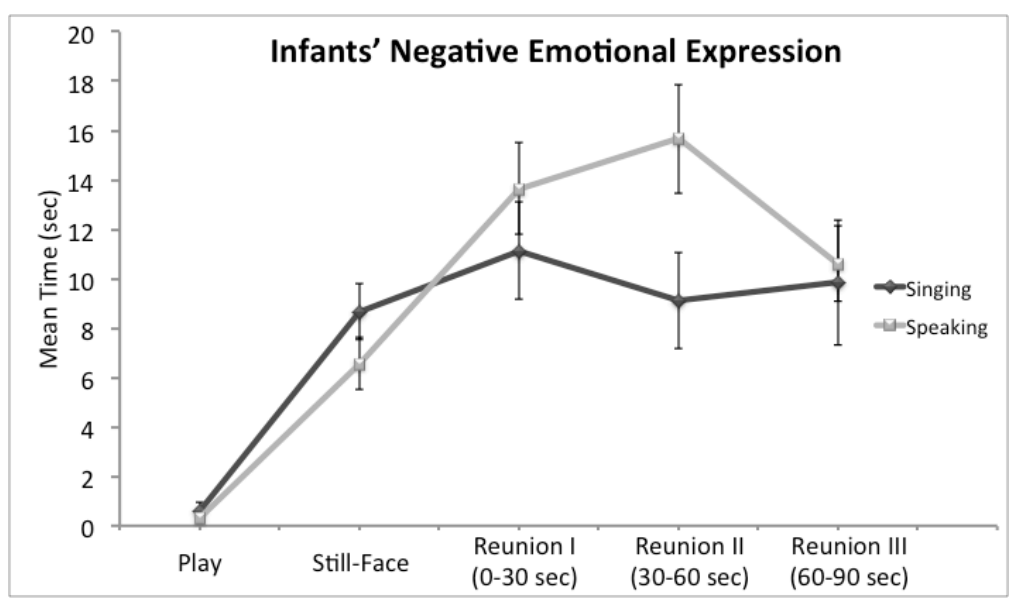

Figure 5: Infants' negative emotional expressions and vocalizations during maternal singing and speaking

\section{Maternal Behaviours}

Facial Expressions. Mean duration of mothers' neutral, negative, contented, and exaggerated facial expressions in the play episode and the three reunion phases, as analyzed using repeated measures ANOVA, revealed no difference in neutral, $F$ $(1,19)=.032, p=.860$, negative, $F(1,19)=3.780, p=.067$, and contented, $F(1,19)$ $=.382, p=.544$, facial expressions in either condition across the time segments (see Table 1). This result notwithstanding, a 4 (time segment) X 2 (condition) repeated 
measures ANOVA revealed a main effect for exaggerated facial expression across time segments, $F(1.84,34.93)=12.18, p<.0001$, with mothers more likely to have highly positive facial expressions during the play episode $(M=2.88 \mathrm{~s}, S E=.35)$ than in the first reunion phase $(M=.39 \mathrm{~s}, S E=.07), F(1,19)=54.59, p<.0001, r=.86$. We further examined mother's exaggerated facial expression using a 3 (time segment) X 2 (condition) repeated measures ANOVA, which revealed a significant main effect for condition during the reunion episode, $F(1,19)=15.94, p=.001$, with mothers displaying more exaggerated expressions while singing $(M=7.70 \mathrm{~s}, S E=$ $.271)$ than while speaking to infants $(M=2.74 \mathrm{~s}, S E=.271)$. A significant interaction indicated that mothers displayed high positive expression differently across conditions during the reunion episode, $F(2,38)=6.11, p=.005$. Specifically, exaggerated expressions were similar across speech and singing conditions during reunion I. For singing, however, duration of exaggerated facial expressions increased from reunion I $(M=.39 \mathrm{~s}, S E=.07)$, to reunion II $(M=4.18 \mathrm{~s}, S E=.90), F$ $(1,19)=9.96, p=.005, r=.59]$, or reunion III $(M=3.03 \mathrm{~s}, S E=.63) F(1,19)=9.49$, $p=.006, r=.58$ (see Figure 6). As can be seen in Table 1, facial expression increased modestly during speech from reunion I to II, but remained well below the levels apparent for singing in reunion II and III. It is also apparent that exaggerated facial expressions were much less common than neutral or contented expressions. 


\begin{tabular}{|c|c|c|c|c|c|}
\hline \multicolumn{6}{|c|}{ Mothers' Facial Expressions } \\
\hline & & Exaggerated & Content & Neutral & Negative \\
\hline \multirow{2}{*}{ Play } & Singing & 3.14 & 7.77 & 14.37 & 0.04 \\
\hline & Speaking & 2.61 & 7.34 & 15.84 & 0.08 \\
\hline \multirow{2}{*}{ Reunion I } & Singing & 0.49 & 7.26 & 14.14 & 0.47 \\
\hline & Speaking & 0.28 & 7.68 & 16.00 & 0.64 \\
\hline \multirow{2}{*}{ Reunion II } & Singing & 4.18 & 6.94 & 14.14 & 0.22 \\
\hline & Speaking & 1.31 & 8.60 & 14.69 & 0.60 \\
\hline \multirow{2}{*}{ Reunion III } & Singing & 3.03 & 7.92 & 15.16 & 0.32 \\
\hline & Speaking & 1.14 & 8.08 & 13.51 & 0.88 \\
\hline
\end{tabular}

Table 1: Mothers' facial expressions across the interaction episode during singing and speaking

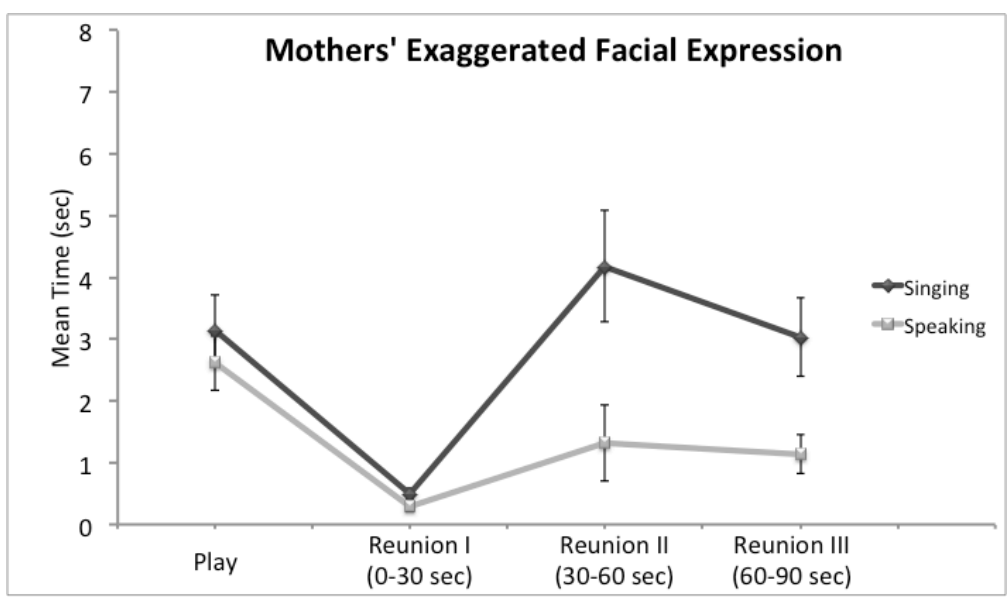

Figure 6: Mothers' exaggerated facial expressions during singing and speaking

Touch. The average duration of maternal embrace, holding, stroking, and rhythmical bouncing of the infant were analyzed in the play episode and the three segments of the reunion phase. No significant differences were evident for embrace in the singing or speaking condition, $F(1,19)=.43, p=.733$.

A 4 (time segment) X 2 (condition) repeated measures ANOVA indicated a main effect of time segment for holding, $F(3,57)=11.08, p<.0001$, where mothers were less likely to hold infants during the play episode than in the reunion episode. A significant interaction indicated differential holding over time as a function of 
condition, $F(3,57)=3.26, p=.028$. Planned contrasts revealed that mothers maintained a longer static hold when speaking during reunion $\mathrm{I}(M=4.44 \mathrm{~s}, S E=$ $.97)$ than during the play episode $[M=.23 \mathrm{~s}, S E=.13), F(1,19)=6.98, p=.016, r=$ .52]. A second planned contrast revealed that in the singing condition, mothers held their infants longer during reunion II $(M=4.60 \mathrm{~s}, S E=1.06)$ than in reunion I $(M=$ $2.34 \mathrm{~s}, S E=.66), F(1,19)=11.92, p=.003, r=.62]$. Overall, mothers cumulatively held infants for 12.42s during speech and 10.80s during singing (see Figure 7).

A 4 (time segment) X 2 (condition) repeated measures ANOVA indicated a main effect of time segment for stroking, $F(3,57)=8.88, p<.0001$, where mothers were less likely to stroke their infant's face or head during the play episode in comparison to the reunion episode. There was also a significant interaction effect indicating that the duration of stroking was different in each condition and across time $[F(3,57)=4.02, p=.012]$. Contrasts revealed that during speech, mothers were more likely to stroke infants during reunion II $(M=3.49 \mathrm{~s}, S E=.88)$ than in reunion I $(M=1.91 \mathrm{~s}, S E=.55), F(1,19)=4.74, p=.042, r=.45$, and in the play episode $(M=.042 \mathrm{~s}, S E=.042), F(1,19)=9.92, p=.005, r=.59]$. Duration of stroking was significantly longer in the speaking condition during reunion III ( $M=$ $2.78 \mathrm{~s}, S E=.87)$ than during the play episode, $F(1,19)=4.77, p=.042, r=.49$. A 3 (time segment) X 2 (condition) repeated measures ANOVA, revealed a significant main effect for condition across the reunion episode suggesting that cumulative duration of stroking was significantly longer during maternal speaking $[M=8.17 \mathrm{~s}$, $S E=.65]$ than singing $[M=3.51 \mathrm{~s}, S E=.50 ; F(1,19)=7.23, p=.015]$ (see Figure 8). 
A 4 (time segment) X 2 (condition) repeated measures ANOVA indicated a main effect for rhythmical movement, $F(2.16,40.98)=3.97, p=.024$, where mothers bounced or rocked their infants longer during reunion II $(M=1.32, S E=$ $.45), F(1,19)=8.59, p=.009, r=.56$, and reunion III $(M=.1 .39, S E=.50), F(1,19)$ $=7.81, p=.012, r=.54$, in comparison to the play episode. A 3 (time segment) $\mathrm{X} 2$ (condition) repeated measures ANOVA, revealed a significant main effect for condition across the reunion episode indicating that cumulative rhythmical movement was greater during maternal singing $(M=6.12 \mathrm{~s}, S E=.73)$ than speech $(M=.92 \mathrm{~s}, S E=.11), F(1,19)=5.61, p=.029$. In short, mothers used touch differently while singing and speaking. During the speech reunion, mothers tended to hold their infants in the first segment, subsequently using more stroking and rubbing gestures in the second and third reunion segments. During the singing condition, however, mothers held their infants halfway into the reunion episode and engaged in more rhythmical movement and touching (see Figures 7, 8, \& 9).

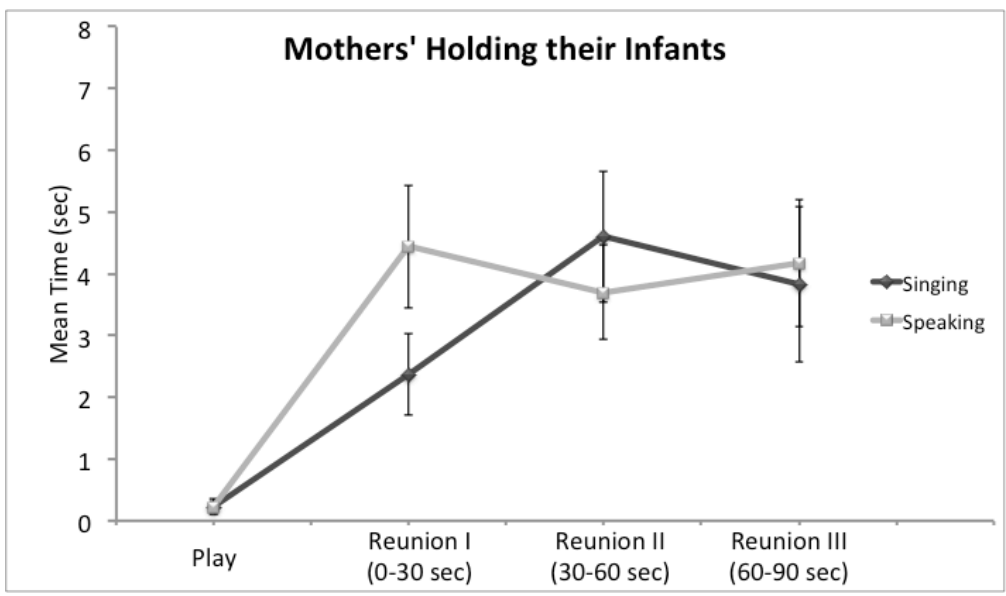

Figure 7: Mothers' holding infants during maternal singing and speaking 


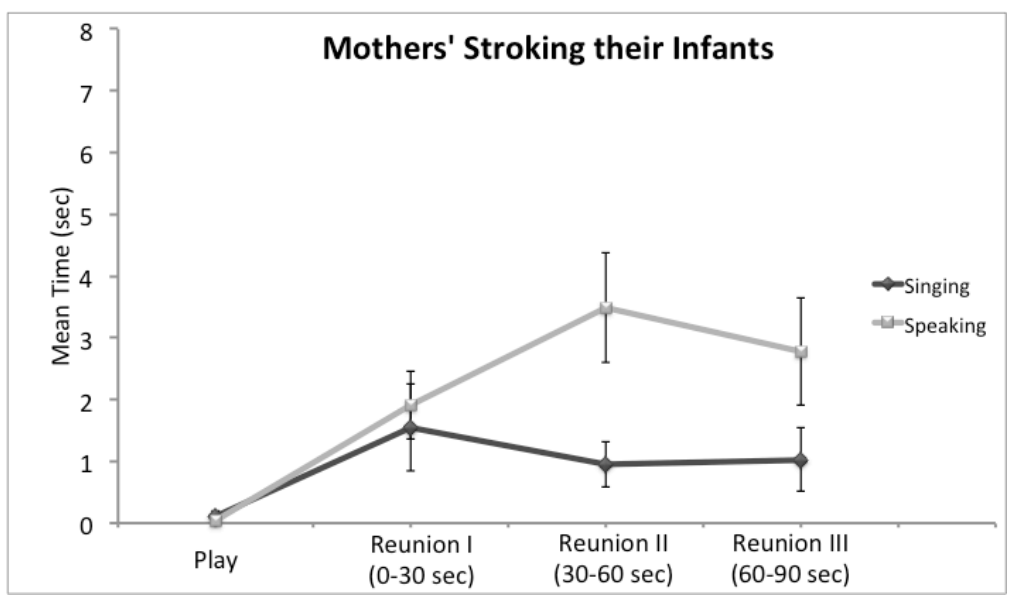

Figure 8: Mothers' stroking infants during maternal singing and speaking

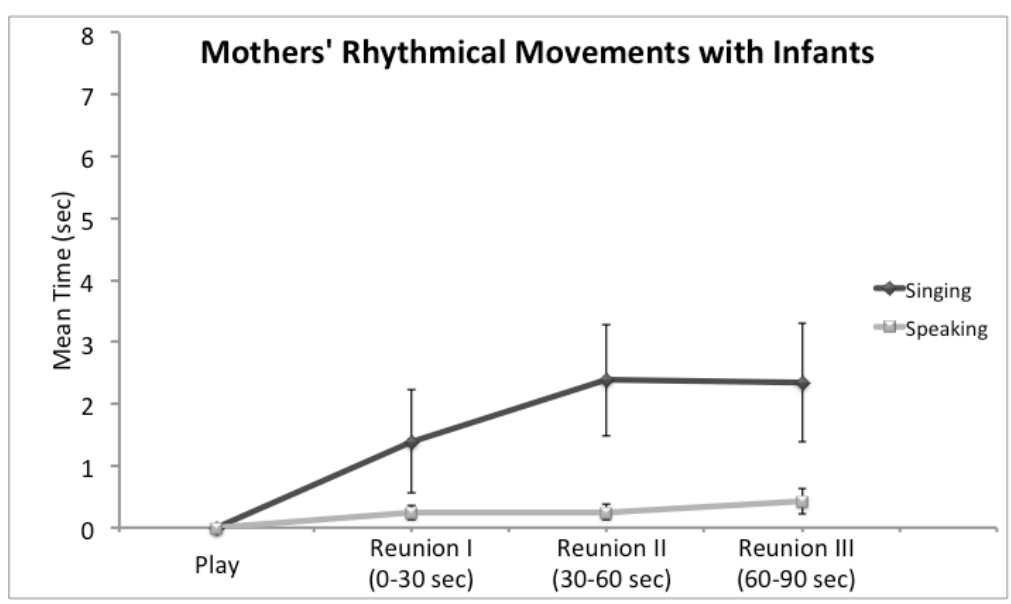

Figure 9: Mothers' rhythmical movements with infants during maternal singing and speaking

\section{Discussion}

The principal goal of the present study was to examine the efficacy of maternal singing and speaking in alleviating infant distress following an acute stressor. Previous work focused almost exclusively on the efficacy of ID speech and singing in attracting and maintaining the attention of non-distressed infants, and few of those studies compared speech and singing directly. In fact, this is the first study to examine the impact of maternal speech and singing on distressed infants. Stress was induced in 10-month-old infants by a modified version of the FFSF 
paradigm so that mothers used speech or singing in successive reunion episodes and were free to engage in a variety of non-vocal behaviours (e.g., touch and facial expressions) in an attempt to reduce infants' distress.

Infants' increased physiological arousal (indexed by SC levels) coupled with their increased duration of negative behaviours (e.g., grimacing, negative vocalizations and decreased visual fixations suggest that stress was effectively induced during the still-face episode. Overall, the context of maternal singing was more effective than the context of maternal speech in ameliorating infants' distress following the still-face, as indicated by SC changes. While infants' SC levels increased beyond the levels of the still-face episode during the first 30 seconds of the reunion in both singing and speech conditions, maternal singing reduced infants' SC levels after 30 seconds into reunion and even further by the third reunion phase (i.e., 60-90 seconds). By contrast, maternal speech dramatically increased (rather than decreased) infants' physiological distress as the reunion progressed. The overall patterns of infants' SC responses to their mother's singing and speaking were especially robust during their first exposure to these conditions. More precisely, as mothers sang, infants' SC levels decreased towards baseline levels far more quickly than what their patterns indicated after doing multiple trials (see Figures 1 and 2). This highlights the cumulative effects of stress on infants, suggesting that maternal singing lost some of its potency after infants were repeatedly subjected to the same stressor (i.e., mother's still-face) over a short period of time. Moreover, the differences in infants' physiological responses during 
the singing and speaking conditions were most pronounced during the last stage of the reunion phase (i.e., $60-90$ seconds). Extrapolations from the data indicated that infants' SC responses would reach baseline levels just after 90 seconds if mothers had continued their singing performances for their infants, but that their SC levels would continue to increase beyond the 90 seconds during the speaking condition.

For the most part, infants' behavioural and physiological responses worked synergistically. During maternal singing, infants exhibited greater sustained attention and intense engagement in comparison to maternal speech. Similar to their SC profiles, infants' negative emotions during maternal singing increased for the first 30 seconds beyond the induced stressor, and subsequently decreased to levels found in the still-face episode as the reunion progressed. During maternal speech, as infants' SC levels escalated across the reunion, their expressions of negative emotions also increased for the first 60 seconds of the reunion (surpassing levels observed in the still-face and singing condition). Accepting these results, infants' behavioural distress in the last reunion phase (i.e., 60-90 seconds) decreased significantly to similar levels as the still-face, thereby highlighting a slight dissociation between the behavioural and physiological indices.

Researchers using other physiological indices (such as vagal tone, heart rate, and cortisol) have reported mixed patterns of findings on the coordination and synchrony between the behavioural and physiological systems. Some researchers have reported that the responses from these two systems are correlated across the still-face paradigm (Moore \& Calkins, 2004; Haley \& Stansbury, 2003). In contrast, 
others report that while the behavioural and physiological systems work in unison during the still-face episode, they become "uncoupled" during reunion (Weinberg \& Tronick, 1996), a finding that is consistent with others who found dissociations between the autonomic and behavioural responses (e.g., Gunnar, Mangelsdorf, Larson, \& Hertsgaard, 1989). In the current study, infants' behavioural and physiological indices were tightly "coupled" during the play phase and still-face episodes. During the reunion episode, infants' attentional responses and engagement (as indexed by visual fixations and reduced motor movements) also worked in unison with their SC levels in both conditions. However, infant's overt negative behavioural expressions became "uncoupled" during the last reunion phase only while mothers were speaking. As Karraker and Lake (1991) observe, infants may often experience stress without producing overt or clear negative emotions to the event. This latter finding is critical because, while infants' SC levels are at their peak in the last reunion segment of the speaking condition, infants' sustained attentional responses (albeit lower than singing) and decreasing fussiness would incorrectly signal to mothers that their infant is being effectively soothed.

The effectiveness of maternal singing in regulating infants' arousal and distress is partly related to the acoustic features of ID singing presented in the outset. Specifically, a series of reports by Trehub and colleagues suggests that infants' greater sustained attention to mothers' singing is due to its distinct characteristics and features. Generally, ID speech has greater pitch variability and exaggerated contours unconstrained by any set patterns. In fact, ID speech can vary 
substantially from one occasion to another and is often saturated with arousing exclamations and non-verbal sounds (Trehub, Hannon, \& Schachner, 2010). ID singing, on the other hand, is bound to musical structures where pitch levels generally increase by one to two semitones (vs. four to five in ID speech) and embellishments in pitch contours are not possible (Trainor, 1996). As a result, the rhythmic regularity in these songs makes maternally sung performances more predictable for infants and highly comforting when distressed. Moreover, mothers' repertoire of songs is also limited; for example, mothers often perform ID songs repeatedly that ultimately become highly familiar and comforting to infants. There is also compelling evidence that mothers perform these limited numbers of songs consistently at nearly identical pitch levels and tempo every time (Bergeson \& Trehub, 2002), which further makes maternal singing more stereotypic and familiar than speech.

General maternal strategies for regulating infants' emotions in the speech and singing conditions were also different. In their daily interactions, mothers often use distraction as a soothing technique when responding to fussing infants (Harman et al., 1997; Jahromi et al., 2004). Whether this pattern of behavior is achieved by presenting the infant with various objects (e.g., keys, rattle), or changing their orientation, mothers often use distraction as a means to shift infants' attention away from aversive stimuli. Although the mothers in this study did not have objects (or toys) and were restricted from picking up their fussing infants, their singing performance successfully distracted upset infants more 
effectively than their speech. Specifically, mothers engaged in a compassionate dialogue while speaking and were even apologetic for having been unresponsive to their infants. That said, in the singing condition mothers were quick to distract their infant by engaging them in rhythmical movements to the beat of their song. This resulted in infants' intense engagement, attention, and regulation of their physiological distress.

It is also important to consider that mother-infant interactions are multimodal and that in the context of singing and speaking to infants, mothers are also employing other strategies, such as the use of their touch and facial expressions in concert with their vocalizations. In fact, touch is an important communication channel that mothers often employ as an "attention-getting" function or as a "nurturing" function in order to facilitate re-engagement (Feldman, Singer, \& Zagoory, 2010; Jean et al., 2009; Jean \& Stack, 2009). In the present study, mothers were also actively utilizing one form of touch to a greater degree, depending on whether they were singing or speaking to infants. Mothers held their infants halfway (i.e., 30-60 seconds) into reunion and generally engaged in more rhythmic movements with their infants by dancing, bouncing, or rocking them while singing. Akin to a choreographed dance, whenever mothers were not bouncing and rocking their infants to their tunes they continued to hold their infants' hands or torso before resuming in rhythmical actions again; this resulted in increased duration of holding during the second reunion episode. These rhythmical interactions not only invite coordinated movements between the dyad (Schogler \& Trevarthen, 2007; 
Trehub \& Nakata, 2002; Trehub, 2003) but as previously mentioned, they are highly distracting and entertaining for the infant as well.

During the context of speaking, however, mothers resorted to holding their infants as soon as they were reunited (i.e., the first 30 seconds), and subsequently engaged in more empathetic behaviours by compassionately stroking and massaging their infants for the remainder of the reunion episode. Mothers' inclination to hold infants upon reunion suggests that they either intuitively knew (or learned very quickly) that their speech alone would not alleviate their infant's distress. As a result, mothers consoled their infants and tried to compensate for and reinforce their utterances by holding and systematically stroking their fussing infants.

As previously outlined, the interaction of mothers in the context of their singing performance and speech invited different types of exchanges between the dyad. The current study provided an ecologically valid means of capturing mother infant interactions where infants' fussing decreased during the last reunion phase of maternal speech, suggesting that mothers' multimodal soothing strategy (i.e., speech with stroking/holding) had some calming effects on infants' negative expressions but not their physiological responses. This finding is consistent with previous studies showing that tactile stimulation (specifically stroking and holding) in combination with vocalizations result in less crying, more eye contact and smiling (Jahromi et al., 2004; Peláez-Nogueras et al., 1996), because mothers' touch provides reassurance and conveys a message of safety (R. G. Campos, 1994; Saarni, 
Campos, Camras, \& Witherington, 2008; Tronick, 1995). In the context of the singing condition however, mothers' rhythmical movements with their infants to the beat of their song effectively distracted and provided a sense of familiarity for the infant. Given the fact that in face-to-face contexts, speech and singing are multimodal rather than mere auditory signals, it is impossible to deduce from the current findings whether these two forms of vocalizations alone (without maternal tactile and facial expressiveness) would have been just as effective in regulating infants' distress. Nevertheless, the findings from this study extend previous work where maternal speech and tactile stimulation alleviated some of the infants' behavioural distress.

The present research examined the contribution of mothers' facial expressions to the efficacy of singing and speech. There are notions that mothers often smile while singing to their infants and this can alter the shape of their vocal tract and vocal quality (Trehub et al., 2010). In fact, when adult listeners (without musical experience) attempt to distinguish ID from non-ID singing, they often justify their judgments on the basis that ID singing has a 'smiling sound' and 'soft or warm voice' (Trehub et al., 2010). In our study, mothers smiled equally in both speaking and singing conditions, making both types of interactions equally warm and inviting for the infant; therefore maternal facial expressions did not contribute to the efficacy of singing in regulating infants' emotions in contrast to the speaking. However, during their singing performance, mothers displayed more exaggerated expressions (with raised brows and wide smiles) after 30 seconds into the reunion. 
Mothers' dramatic facial expressions enhanced the playful nature of the interaction in comparison to the speaking condition where mothers appeared to be less "emotionally charged". Infants are very attentive to positive emotional tones (Corbeil et al., 2013; Fernald, 1993; M. Papoušek et al., 1990), prefer positive facial expressions (Kuchuk, Vibbert, \& Bornstein, 1986), and after about 6 months of age show signs of understanding cross-modality correspondences in emotional expression (Walker-Andrews, 1986, 1988). In their everyday social interactions, caregivers provide vital information to their infants using different facial expressions (along with vocalizations and touch) which provide the infant with implicit and explicit messages (Ham \& Tronick, 2009). Through social referencing, infants use the affective messages relayed by their mother to understand their own emotional experience as well as ambiguous social situations (Campos \& Stenberg, 1981; Ham \& Tronick, 2008, 2009; Saarni et al., 2008). Therefore, mothers' singing, combined with her animated facial expressions, provides the infant with a more salient signal as to how to respond to the situation, whereas such a message is more subdued in the speaking condition.

Finally, it is important to expand on the results that reveal infants' increased physiological and behavioural distress during the first 30 seconds of reunion subsequent to the still-face episode. One explanation for this finding is that the induction of stress during the still-face had not resolved, and it took some time before mothers' vocalizations began to show their true disposition and ability in regulating the emotions of distressed infants. Moreover, the mother's still-face not 
only poses a different type of stressor (vs. a stressor from a painful procedure), but mothers are also the agents or 'culprits' in having triggered the infant's distress in the first place (vs. an injection from a physician). This outcome presents a different, albeit difficult, challenge for the infant who may be initially unsure about how to respond to their mother. It is also plausible that infants' fussing and protests during the still-face affected mothers' own regulatory processes; that is, mothers had to deal with their own guilt and stress after helplessly watching their infants' negative expressions from the still-face episode. In fact, mothers' display of exaggerated facial expressions was also lower during the first 30 seconds of reunion in the singing condition. Consistent with this line of argument, Ham and Tronick (2009) found that "a mother trying to calm her infant, calms herself physiologically" as she attempts to mend the break in the social interaction (p. 628). Taken together, the findings of this study support the notion that it is generally not easy for infants to recover from a challenging situation such as the still-face and that without the mother's appropriate soothing strategy (in this case, maternal singing), infants' physiological and behavioural displays can snowball and prolong the recovery process during reunion.

By documenting the function of infants' behavioural and physiological responses to maternal singing and speech, and demonstrating how the functions vary across interaction periods, the current study has taken an important step in revealing the links between these measures and the role of maternal voice in regulating infants' emotions. While researchers in the past have examined infants' 
responsiveness to maternal vocalization, the current study is the first to directly examine the effects of maternal singing and speaking on infants' emotions in response to a stressor using skin conductance in parallel with behavioural measures. The results reveal that maternal singing not only captured and sustained infants' attention and intense engagement but it also successfully decreased their physiological stress. In conclusion, our findings indicate that maternal singing regulates infants' distress and arousal more effectively than speaking. However, given that most north American mothers sing play songs (as did most mothers in this study) (e.g., Shenfield et al., 2003), it will be important to decipher what would be the effects of different genres of maternal singing (i.e., play songs and lullabies) in regulating infants' distress. 


\section{CHAPTER 3 : THE EFFECT OF MATERNAL PLAY SONGS AND LULLABIES ON DISTRESSED INFANTS (STUDY 2)}

Infants' expressions of distress are responses to internal states such as hunger and physical discomfort or to external situations involving social or environmental factors (Karraker, Lake, \& Parry, 1994). Caregivers, usually mothers, have the primary responsibility of responding to infants' distress in a way that reduces their arousal (Eisenberg, Fabes, \& Murphy, 1996; Thompson, 1994). Understanding the efficacy of maternal intervention in alleviating infant distress is important in light of the association between effective emotion regulation in infancy and positive social outcomes (Denham et al., 2003; Eisenberg, Cumberland, \& Spinrad, 1998; Eisenberg, Fabes, Murphy, et al., 1996).

Despite widespread acknowledgement that mothers play a critical role in modulating infant's arousal (e.g., Kopp, 1989; Thompson, 1994), there has been little research on the efficacy of various maternal soothing strategies in alleviating infant distress. One study examined the effect of maternal soothing on 2- and 6month-old infants' distress during every day caregiving and after inoculation (Lewis \& Ramsay, 1999). The results showed comparable maternal soothing strategies across contexts, although mothers use these strategies more often to soothe infants after inoculation. In addition, while mothers typically use more proximal (e.g., holding and rocking) than distal behaviours (e.g., soothing voice, emotional expressions), there was no evidence that maternal soothing behaviour reduced infant cortisol levels or negative behaviours. In another study of maternal responses 
to infant inoculation-induced distress, maternal touch and expressions of affection decreased from 2- to 6-months of age, but maternal vocalization and distraction behaviours increased during the same period (Jahromi et al., 2004). A common means of distracting infants is to shift their attention away from a distressing event and toward an interesting visual object or event. After 3-and 6-month-old infants became upset from viewing uninteresting computer displays of changing shapes and tones, the presentation of a toy succeeded in calming them but their distress returned to previous levels when the toy was withdrawn (Harman et al., 1997). In other words, this type of distraction had transient rather than sustained effects on infant distress.

In principle, maternal vocalization, singing in particular, could have more sustained effects on emotion regulation and is thus important to examine, especially since singing is a universal form of caregiving (de l'Etoile, 2006; Shenfield, Trehub, \& Nakata, 2003). Mothers across cultures sing to infants as a means of maintaining playful interactions, soothing fussy infants, and while engaging in instrumental activities such as diaper changes, bathing, and preparation for sleep (Nakata \& Trehub, 2004; Trehub et al., 1997). Infants are differentially responsive to infantdirected (ID) over non-ID singing from the newborn period (Masataka, 1999; Trainor, 1996).

Mothers also speak melodiously to infants in the course of providing care (e.g., Fernald \& Simon, 1984; H. Papoušek, 1996; M. Papoušek, 1994). From the newborn period, infants listen preferentially to ID over adult-directed (AD) speech 
(Cooper \& Aslin, 1990; Fernald, 1985; Werker \& McLeod, 1989). The presumption is that infants' preference for ID speech arises largely from its musical qualities, which transmit emotional information (e.g., Fernald, 1989, 1991; M. Papoušek, 2007).

Despite the presumption that maternal speech and singing play an important role in modulating infant arousal (Fernald, 1991; Trehub \& Trainor, 1998), there has been little empirical evaluation of that claim aside from Experiment 1 and an earlier demonstration that maternal singing modulates salivary cortisol levels in infants (Shenfield et al., 2003). Previous research has focused largely on attentional rather than arousal consequences of speech or singing (e.g., Cooper \& Aslin, 1990; Fernald, 1985; Trainor, 1996), with few direct comparisons of the effects of speech and singing. One such comparison indicated that infants attended longer and more intensely to audiovisual recordings of maternal singing than to maternal speech (Nakata \& Trehub, 2004). Another revealed that infants listened longer to happy rather than neutral-sounding vocalizations, whether spoken or sung (Corbeil et al., 2013).

Experiment 1 provided the first comparison of the relative efficacy of maternal singing and speech in regulating infant arousal and emotion. After infant distress was induced by the face-to-face-still-face (FFSF) procedure, maternal singing was more effective than speech in ameliorating such distress. Neither maternal intervention succeeded in returning infants' arousal to pre-still-face levels, but the changing pattern of skin conductance and negative behaviour over 
the course of the reunion episode revealed more favourable outcomes for maternal singing. In fact, infant arousal and negative vocalizations increased steadily during the reunion episode with maternal speech, with no evidence of a turnaround. Arousal and negative vocalizations also increased initially during the reunion episode with maternal singing, but they leveled off and reversed direction by the last phase of the reunion. In addition, infants responded to maternal singing with reduced motor activity, which is thought to reflect intense attention (Nakata \& Trehub, 2004).

Although maternal singing proved better at regulating infant emotion than maternal speech, it was unclear which aspects of maternal singing were responsible for the favourable effects. It is possible that in the Experiment 1, the prescribed lyrics of songs facilitated the delivery of expressive performances. Also, mothers varied in the type of songs they sang, with most singing lively play songs and a minority singing lullabies, which precluded comparisons of song type.

Although lullabies and play songs are universal modes of interacting with infants, their use varies across cultures. Lullabies, which are characterized by simplicity, repetitiveness, and descending pitch contours, are used by Western caregivers to induce sleep and by non-Western caregivers to maintain infants in a calm and contented state throughout the day (Trehub et al., 1993; Trehub \& Trainor, 1998; Unyk et al., 1992). Play songs, with their greater rhythmicity, dynamic variation, and exuberance, are used to heighten infant arousal and engagement (Rock et al., 1999; Trainor, 1996). In contrast to Western mothers, 
whose ID vocalizations are primarily playful, the ID vocalizations of non-Western mothers' ID are primarily soothing (Trehub, Trainor, \& Unyk, 1993; Trehub \& Trainor, 1998; Unyk et al., 1992). Despite the distinctions and different uses of play songs and lullabies, it is not clear which of these genres would be more effective in reducing infant's distress. Maternal lullaby singing could be considered an empathic response to infant distress, which could indicate sensitivity and attunement to infant emotion (see Trehub \& Trainor, 1998). By contrast, maternal singing of rhythmic play songs could be viewed as a means of distracting infants (see Milligan, 2000).

Therefore, the purpose of the present experiment was to compare maternal lullabies and play songs as vehicles for ameliorating distress in 10-month-old infants. In general, Western mothers shift from soothing emotion regulation strategies with younger infants to distracting strategies with older infants (Craig, McMahon, Morison, \& Zaskow, 1984), which might suggest that play songs might have greater efficacy than lullabies in alleviating distress. Notwithstanding, the widespread use of lullabies across cultures and historical periods may be attributable to their efficacy in emotion regulation. It is possible, moreover, that lullabies might achieve their emotion regulatory goals more slowly than play songs but result in longer lasting states of calm. As in Experiment 1, infant distress was induced by the FFSF procedure. The reunion episodes featured maternal lullabies on some trials and maternal play songs on an equal number of trials. The outcome measures, as in Experiment 1, involved skin conductance (SC) and infant 
behaviours, including infant visual attention, infants' suspended motor activity (a sign of intense activity, see Nakata \& Trehub, 2004) and negative facial and vocal expressions.

\section{Method}

\section{Participants}

The participants were 32,10 -month-old infants (10 boys, 22 girls, $9.5-10.8$ months). Infants were excluded due to fatigue and crying $(n=4)$; fussing exceeding 30 seconds during the reunion episode $(n=3)$ in the lullaby condition, which precluded comparisons with the play song condition; and technical errors such as improperly attached electrodes or mothers obscuring the infant's face $(n=5)$. The 20 infants in the final sample (mean age $=10.1$ months; 8 boys, 12 girls) were healthy, born at term, and had no family history of hearing loss. Most infants were first-born (80\%), and the ethnic composition of the sample was European (65\%), Asian (20\%), and mixed (15\%).

All mothers reported singing to infants $(n=20)$ for an average of 94 minutes per day whether for playful or soothing purposes. Mothers reported singing soothing lullabies primarily at bed time $(n=11)$, when the infant was fussing $(n=4)$, at bath-time $(n=1)$, whenever necessary $(n=2)$, while others reported not singing soothing songs at all $(n=2)$. All mothers reported singing lively play songs to their infants primarily when playing with them $(n=6)$, throughout the day $(n=12)$, car rides $(n=1)$, and in baby time classes $(n=1)$. Infants were also exposed to singing by other family members such as the infants' father $(n=14)$, grandparents $(n=8)$, 
aunts, cousins and extended caregivers $(n=3)$, and in day care $(n=1)$, for an average of 45 minutes per day. Majority of infants also watched or listened to television or video program that contained sing-a long activities $(n=13)$ for approximately 22 minutes per day. All mothers reported that their infants were also exposed to recorded audio music throughout the day $(n=20)$, as well as to musical toys $(n=20)$ for approximately 77 minutes and 83 minutes per day. Some mothers also reported playing musical instruments for their infants $(n=8)$ for approximately 24 minutes per day.

\section{Apparatus}

The apparatus was the same as that used in Experiment 1.

\section{Procedure}

The procedure was similar to that of Experiment 1. Mothers completed a Child Pre-Observations Questionnaire (CPOQ) inquiring about infants' development, complications, as well as their exposure to music and singing by caregivers (see Appendix 2). As before, mother and infant engaged in a three stage interaction: 1) face-to face play episode, 2) mother's display of neutral still-face and, 3) the reunion episode. During the play episode, mothers engaged in at least 60 seconds of play (using soundless toys) and were then asked to retrieve the toys and place them in a box, out of the infant's view. Once mothers looked away from the infant (to their left) for 5 seconds, they returned to face the infant with a still and neutral facial expression for 20 seconds. During the still-face episode, mothers were asked to maintain eye contact with infants but to refrain from vocalizing, 
smiling/frowning, or touching infants. In the subsequent reunion episode, mothers were asked to sing one or more soothing lullabies or lively play songs for 90 seconds. In the lullaby condition, mothers were instructed to sing soothing songs (e.g., Twinkle Twinkle; Rock-a-Bye Baby) that they usually used for lulling their infants to sleep. In the play song condition, mothers were instructed to sing lively songs that they usually used for engage and play with infants. Some mothers sang the same song repeatedly for the entire reunion episode, but most sang various songs from the appropriate genre. Infants were exposed to 3 trials each of lullaby and play song reunion for a total of 6 trials over a 20-minute session. The experimenter counter balanced the conditions, where half of the mothers sang play songs during their first reunion episode, while the others sang lullabies. The presentation of the conditions from thereon was randomized.

If infants fretted for more than 30 seconds $(n=3)$ or mothers asked to stop the session $(n=0)$, the session was terminated. To minimize carry-over effects of stress from the preceding trial, play episodes were extended as needed to ensure that infants were calm and alert. The play period was extended on 22 trials which were generally granted towards the latter part of the experiment to allow the infant to recuperate from the repeated exposure to the still-face. If infants fretted for more than 30 seconds during the reunion or play episodes, the session was interrupted and mothers were asked to soothe infants using toys or to pick them up if necessary. Once the mother agreed that the infant was calm, the session resumed with a new trial starting at the play episode. 


\section{Behavioural Coding}

As in Experiment 1, behavioural measures were coded as total durations during each time interval corresponding to the physiological intervals (i.e., the last 30 seconds of the play episode, last 20 seconds of the still-face episode, and three 30second intervals in the reunion episode). Infants' visual fixation, physical activity, and negative emotional valence were coded for each of the five time segments (i.e., play episode, still-face episode, reunion I, reunion II, and reunion III). To assess inter-rater agreement, $20 \%$ of the sample was re-coded by a third, trained coder who was blind to the goals of the study. Agreements were scored when both coders observed the same behaviour within 1 second of each other and quantified using kappa to correct for chance agreement. Overall, inter-rater reliability for infants' visual fixation, suspended motor activity and negative emotional reactions were $k=$ $.94, k=.91, k=.93$, respectively.

\section{Results}

During the reunion episode, mothers used a range of material including well-known children's songs (e.g., Old MacDonald had a Farm; Hush, Little Baby), invented songs (e.g., original tunes incorporating the infant's name), and non-English play songs and lullabies. Infant gender was unrelated to the physiological variables and behavioural measures. Therefore, these factors were not considered in subsequent analyses. As in Experiment 1, not all infants displayed negative vocalizations, fussing and increased SC levels during the still-face episode. Because the study's aim was to examine the effects of maternal singing in regulating the emotions of distressed infants, the trials in which infants did not exhibit a physiological arousal or negative behavioural 
response to their mother's still-face were dropped from the final analyses $(n=6$ trials). The 20 infants contributed 118 trials (60 play songs, 58 lullabies) for analyses, with each infant contributing at least 2 trials to each condition. More specifically, 18 infants contributed six trials (54 singing and 54 speech trials), and 2 infants contributed five trials (6 singing and 4 speech trials).

\section{Infants' Skin Conductance Levels}

From Play Episode to Still-face Episode. Before addressing the central question of which song genre would most effectively reduce infant distress, we verified whether the FFSF paradigm induced infant distress in the play song and lullaby conditions. A 2 (time segment) X 2 (condition) repeated measures ANOVA on the standardized SC values ( $z$-scores) revealed a significant main effect of time segment, $F(1,19)=15.32, p=.001$, indicating that infant distress was effectively induced.

Across Interaction Episodes. We examined mean SC changes across the play episode, still-face, and three time segments of the reunion phase. A 5 (time segment) X 2 (condition) repeated measures ANOVA revealed that Mauchley's test of sphericity was violated for time segments, $\varepsilon=.56 ; X^{2}(9)=47.80, p<.05$, and the interaction, $\varepsilon=.51 ; X^{2}(9)=62.23, p<.05$, so degrees of freedom were corrected using Greenhouse-Geisser estimates of sphericity. There was a significant main effect of time, $F(2.25,42.66)=15.81, p<.0001$, indicating that in comparison to the play episode, SC levels increased during the still-face and reunion episodes. There was also a significant interaction between condition and time, $F(2.03,38.62)=5.22$, 
$p=.01$, indicating that the mother's voice had different effects on infant SC level in different phases of the interaction. Contrasts between maternal play song and lullaby conditions were conducted comparing all interaction episodes to the baseline (play episode). The analysis revealed a significant interaction where infant stress levels in reunion III were significantly lower as mothers sang play songs $(M=.24$, $S E=.098)$ than lullabies $(M=.93, S E=.14 ; F(1,19)=7.31, p=.014, r=.53)$.

Across Reunion Segments. Although SC levels decreased over the course of the singing condition at reunion differences between maternal play song and lullaby conditions were further examined across the reunion segments. A 3 (reunion time segment) X 2 (condition) repeated measures ANOVA revealed a significant main effect for condition, $F(1,19)=5.32, p=.033$, where infants exhibited lower SC levels during playful singing $(M=.41, S E=.093)$ than during lullaby singing $(M=$ $.87, S E=.13)$. There was also a significant interaction between condition and reunion segment, $F(1.24,23.50)=6.32, p=.014$. Planned contrasts revealed that SC levels during the play song condition were significantly lower in reunion III than in reunion I, $F(1,19)=7.05, p=.016, r=.41$, or reunion II, $F(1,19)=6.73, p=$ $.018, r=.52$. As illustrated in Figure 10, SC levels during the play song condition decreased from reunion I $(M=.52, S E=.12)$ to reunion II $(M=.47, S E=.10)$, and to reunion III $(M=.24, S E=.10)$, while SC levels increased and remained high during the lullaby condition from reunion I $(M=.77, S E=.14)$ to reunion II $(M=$ $.92, S E=.14)$ and to reunion III $(M=.93, S E=.14)$. 
Infants' SC levels were significantly lower in the play song than in the lullaby condition from 60 seconds into the reunion phase, with the greatest difference between conditions occurring in the final reunion phase. Quadratic extrapolations of the data indicate that, for play songs, SC would return to pre-SF levels shortly after 90 seconds of reunion. Similar extrapolations indicate that SC would eventually decrease in response to maternal lullabies, but the effects would take significantly longer.

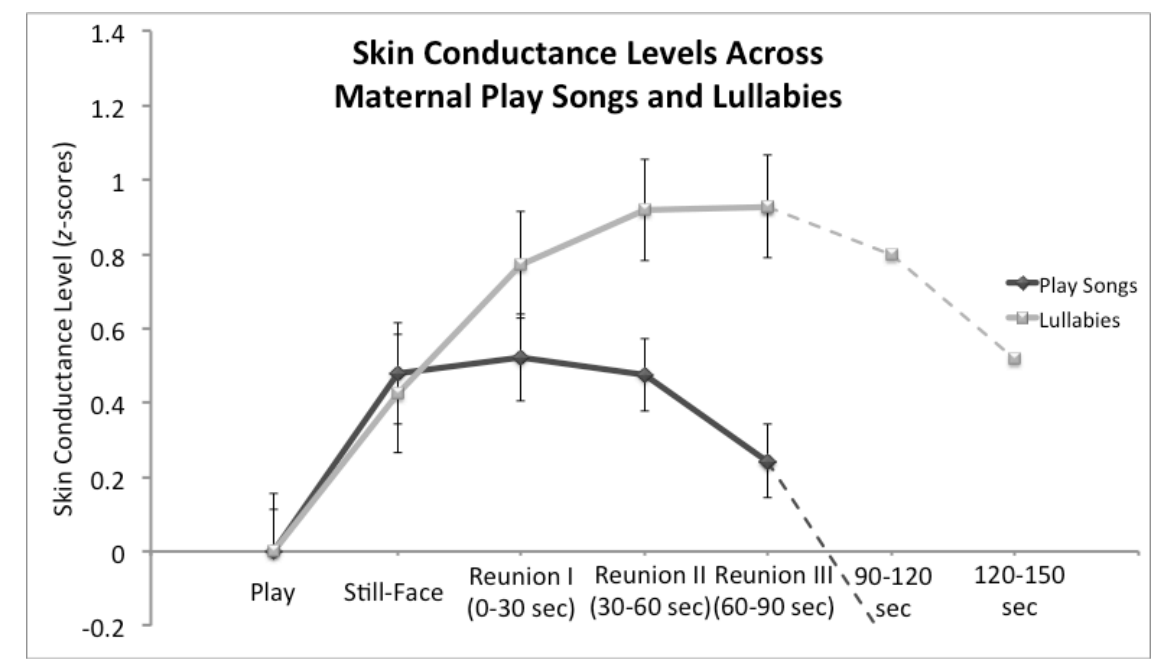

Figure 10: Infants' skin conductance levels during maternal play songs and lullabies

First Trial with Play Songs and Lullabies. It is possible that stress was induced only after repeated exposure to the FFSF paradigm rather than on the first trial. We examined the first reunion episode involving lively or soothing singing, 
with 22 infants ${ }^{2}$ contributing data for the analyses, 12 receiving a lullaby and 10 a play song. A 2 (time segment) X 2 (condition) repeated measures ANOVA revealed a significant main effect of time segment, $F(1,21)=11.68, p=.001$, indicating that stress was effectively induced on the first trial.

A 5 (time segments) X 2 (conditions) repeated measures ANOVA revealed that Mauchley's test of sphericity was violated for time segments, $\varepsilon=.59 ; X^{2}(9)=31.40$, $p<.05$, and the interaction, $\varepsilon=.54 ; X^{2}(9)=46.83, p<.05$. Degrees of freedom were corrected using Greenhouse-Geisser estimates of sphericity. The ANOVA revealed a significant main effect of time segment, $F(2.37,49.67=10.35, p=.0001$, reflecting an increase in SC levels from the play episode to the still-face and reunion phases. There was a significant interaction between time segment and condition, $F(2.15$, $45.04)=3.52, p=.035$. Planned contrasts revealed that during the lullaby condition, SC levels increased significantly from the still-face episode $(M=.33, S E=.19)$ to the first reunion phase with lullabies $(M=.77, S E=.20), F(1,21)=4.37, p=.049, r$ $=.36$. Although SC levels also increased from the still-face episode $(M=.58, S E=$ $.13)$ to the first reunion phase with play songs, $[M=.65, S E=.14]$, the increase was more modest in the play song condition.

2 The examination of infants' first exposure to maternal play songs and lullabies resulted more infants being included $(n=2)$ who were excluded from the overall analyses due to fussiness in subsequent trials. 
A 3 (time segment) X 2 (condition) repeated measures ANOVA with SC levels as the dependent measure revealed no effect of condition, $F(1,21)=2.06, p=.166$, or time segment, $F(2,42)=.33, p=.671$, and no interaction, $F(2,42)=3.16, p=$ .079 (see Figure 11).

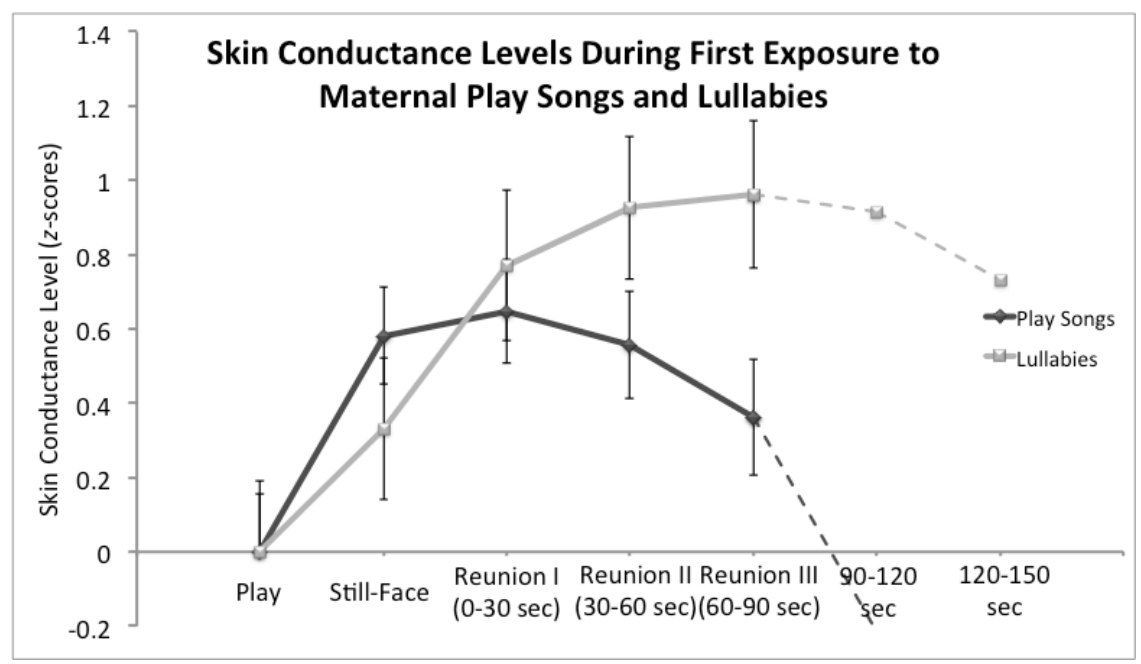

Figure 11: Infants' skin conductance levels during first exposure to maternal play songs and lullabies

\section{Infant Behaviours}

Visual Fixation and Intensity of Engagement. Visual fixation on mother's face during play songs and lullabies was examined across interaction episodes. A 5 (time segment) X 2 (condition) repeated measures ANOVA revealed a significant main effect of time segment, $F(4,76)=69.58, p=.0001$. Planned contrasts revealed that in comparison to the play phase $(M=1.79 \mathrm{~s}, S E=.53)$, infants exhibited greater fixation on mother during the reunion episodes $[M($ reunion $I)=9.55 \mathrm{~s}, S E=.93 ; M$ $($ reunion $I I)=8.76 \mathrm{~s}, S E=.95 ; M($ reunion $I I I)=9.39 \mathrm{~s}, S E=.99]$. However, there were no significant differences in visual fixation between the play episode and the still-face $[M=2.09 \mathrm{~s}, S E=.43 ; F(1,19)=.41, p=.528]$. Infants increased their gaze 
at mother from the still-face episode to reunion I, $F(1,19)=100.72, p=.0001, r=$ .92 , from still-face to reunion II, $F(1,19)=89.30, p=.0001, r=.91$, and from stillface to reunion III, $F(1,19)=95.25, p=.0001, r=.91$. Further analysis of infants' gaze during the play episode indicated that infants looked at the toys $(M=26.68 \mathrm{~s}$, $S E=.83)$ more than at the mother's face $(M=1.79 \mathrm{~s}, S E=.53), F(1,19)=373.69, p$ $=.0001$.

A 3 (time segment) X 2 (condition) repeated measures ANOVA revealed a significant main effect of condition on visual fixation in the reunion episode, $F$ (1, 19) $=42.13, p=.0001$, reflecting greater cumulative fixation during playful singing $(M=37.35 \mathrm{~s}, S E=1.12)$ than during soothing singing $(M=18.05 \mathrm{~s}, S E=.91)$. There was also a significant interaction effect between condition and the reunion time segment, $F(2,38)=4.27, p=.025$. Planned contrasts revealed that during lively play songs, infants significantly increased their gaze at or toward the mother from reunion I $(M=11.71 \mathrm{~s}, S E=1.12)$ to reunion II $(M=12.44 \mathrm{~s}, S E=1.34) F(1,19)=$ $5.90, p=.025, r=.49$, and from reunion I to reunion III $(M=13.21 \mathrm{~s}, S E=1.30), F$ $(1,19)=5.51, p=.030, r=.47$ (see Figure 12). A 3 (time segment) X 2 (condition) repeated measures ANOVA on infants' body activity while gazing at mother revealed a significant main effect for condition, reflecting more intense engagement with playful maternal singing $(M=28.12 \mathrm{~s}, S E=1.01)$ than with soothing maternal lullabies $(M=11.45 \mathrm{~s}, S E=.67), F(1,19)=30.81, p=.0001$ (see Figure 13).

Negative Affect during Reunion. Duration of negative affect, including negative facial expression and vocalizations, were considered. A 2 (time segment) $\mathrm{X}$ 
2 (condition) analysis revealed that infants exhibited more negative affect during the still-face $(M=9.67 \mathrm{~s}, S E=.98)$ than the play episode $(M=.42 \mathrm{~s}, S E=.18), F(1$, 19) $=102.74, p=.0001$. Moreover, a 3 (time segment) $\mathrm{X} 2$ (condition) repeated measures ANOVA revealed a significant main effect for condition across the reunion segments, $F(1,19)=4.80, p=.041$, reflecting greater cumulative duration of negative affect during maternal lullabies $(M=29.72 \mathrm{~s}, S E=2.03)$ than play songs $(M=21.57 \mathrm{~s}, S E=1.49)($ see Figure 14$)$.

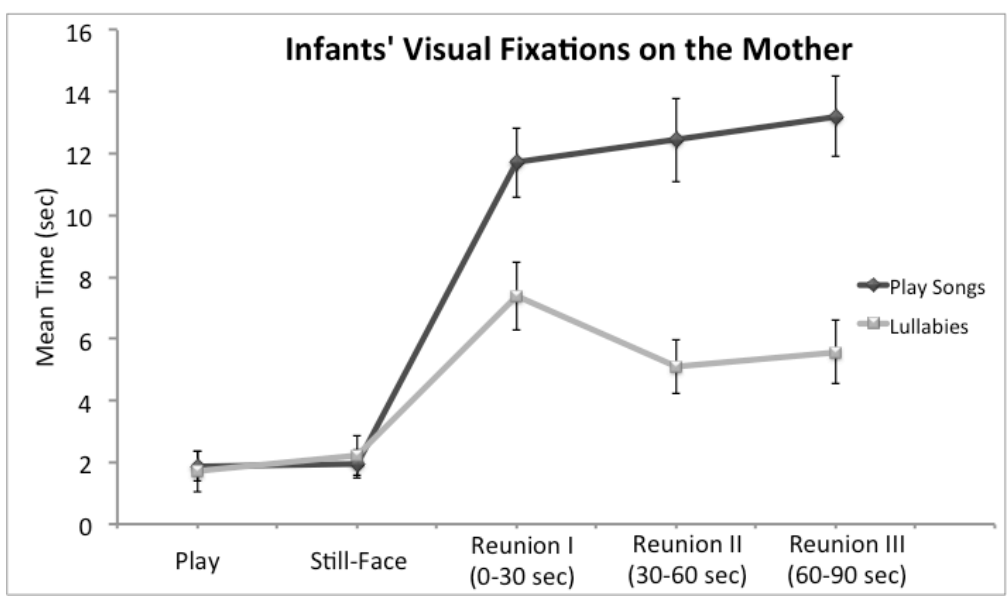

Figure 12: Infants' visual fixation on the mother across the reunion episode during maternal play songs and lullabies

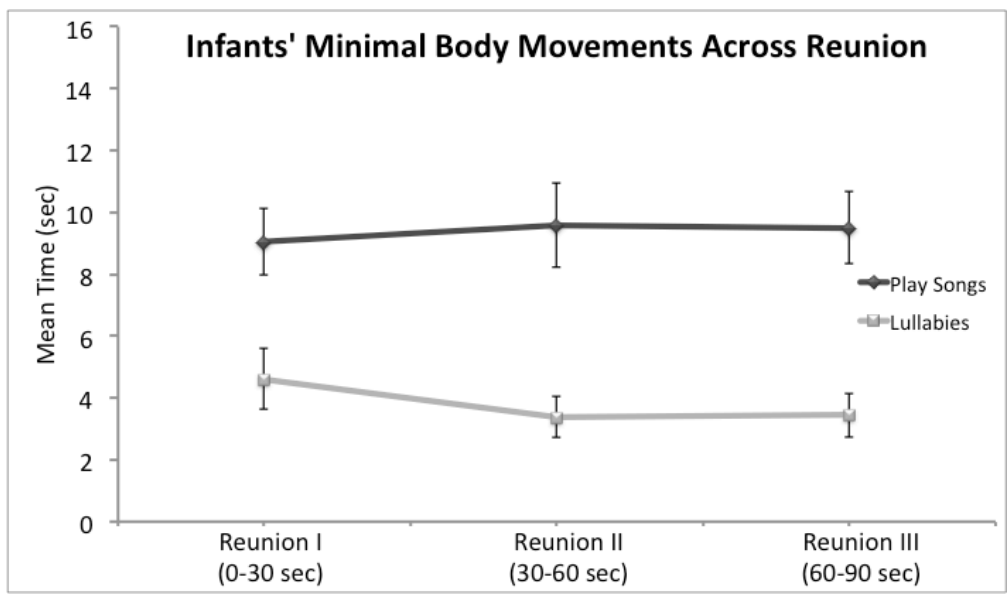

Figure 13: Infants' minimal body movements accompanied by visual fixation during maternal play songs and lullabies 


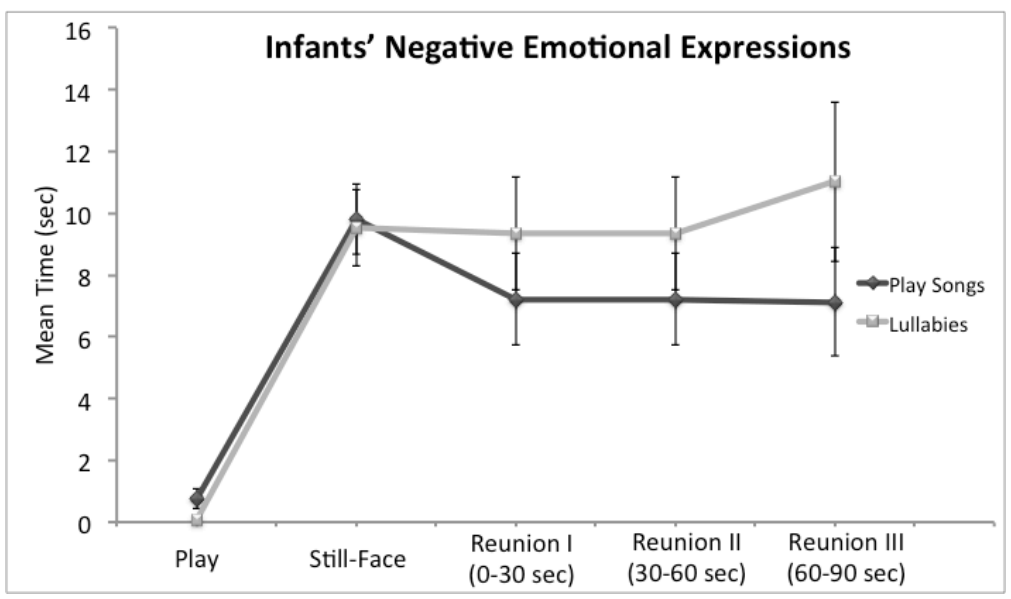

Figure 14: Infants' negative emotional expressions and vocalizations during maternal play songs and lullabies

\section{Discussion}

The present experiment was the first to compare the relative efficacy of maternal play songs and lullabies in regulating emotion and attention in distressed infants. Distress was indexed by skin conductance (SC) levels and negative behavioural responses, and attention was indexed by visual fixation and reduced body movement. Although maternal singing following the induction of infant distress effectively captured infants' attention, as revealed by visual fixation of mother and reduced body movement, infants' SC levels revealed continued distress, even after the onset of maternal singing. During the first 30 seconds of the reunion episode, SC levels increased significantly during lullaby singing but only marginally during play song singing. After 30 seconds into the reunion episode, SC levels decreased during play songs but continued to increase during lullabies. Infants' first exposure to each condition was more profound in comparison to the overall findings (i.e., repeated exposures to each conditions), where the largest difference in infants' 
stress was observed during the last phase of the reunion (i.e., 60-90 seconds), with levels decreasing more quickly towards baseline during maternal play songs.

Infants' behavioural responses mirrored their physiological responses in the sense that infants exhibited less negative affect during play songs than during lullabies. During maternal lullabies, infants became increasingly distressed and displayed more negative emotions and vocalizations beyond the induced stressor. Although negative affect in the play song reunion did not return to the low levels evident in the play episode, such behaviours decreased relative to levels observed during the still-face episode. Moreover, infants' visual fixation on the mother and their pronounced reduction in motor activity during play songs confirmed their absorption in this maternal intervention. While infants' recovery from distress may at first appear to be more rapid when viewed through a behavioural rather than a physiological lens, infants' SC levels showed a decreasing pattern across the reunion phase that was not evident behaviourally. Comparable dissociations between skin conductance and behaviour were evident in the reunion phase of Experiment 1 and have been reported elsewhere (e.g., Gunnar et al., 1989; Weinberg \& Tronick, 1996). Nevertheless, the findings clearly indicate that maternal play songs were considerably more effective than maternal lullabies in modulating infant arousal.

Although maternal play songs did not result in the low SC or negative affect levels observed in the play episode, extrapolations of the data suggested that infant SC levels would have returned to those levels had the reunion episode continued 
shortly beyond 90 seconds. Maternal lullabies were not entirely ineffective, as reflected in infants' attention. That said, extrapolations suggested that it would take over 2.5 minutes to reverse the SC trajectory and approach baseline levels. An important task of future research is to extend the reunion session to ascertain the entire course of infants' recovery from distress.

What can account for the much greater efficacy of lively compared to soothing singing? It may seem counter-intuitive that a song genre designed for soothing infants is less effective in ameliorating distress than play songs were. Kopp (1989) notes, however, that maternal soothing behaviours are related to "infants' age, [...], situational factors (e.g., time of day and toy availability), level of distress, and messages given by the caregiver" (p. 345). There are developmental changes in maternal strategies of emotion regulation. For example, distracting maternal vocal and non-vocal behaviours are used increasingly with infants older than 6 months of age, in contrast to vocal and non-vocal soothing behaviours with younger infants (Jahromi et al., 2004; Lewis \& Ramsay, 1999). Lullabies are also used more commonly in early infancy for comforting infants, in contrast to play songs, which provide stimulation and information that is more suitable for older infants (Craig et al., 1984; Trehub \& Trainor, 1998). It is possible, then, that lullabies might have greater efficacy with younger infants as well as those from other cultures than they did for the distressed 10-month-olds in the current experiment.

For 10-month-olds, daytime might be more suitable for lively rather than soothing activities, especially when infant distress is not accompanied by physical 
pain. Although infants were clearly distressed by the disconcerting experience of their mother's cessation of social interaction during the still-face episode, it is possible that they would have reacted more favourably had their mother simply resumed her "normal" manner of interaction, especially if she introduced toys. Although maternal speech in Experiment 1 constituted a "normal" mode of maternal interaction, it was ineffective in alleviating infant distress.

According to Rock et al. (1999), play songs invite infants to "pay attention and have fun," in contrast to lullabies, which invite infants to "calm down and go to sleep" (p. 532). This difference in function is decidedly Western, as the non-Western message of lullabies is that "all is well" (Trehub \& Trainor, 1998). For most of the infants in the present sample, lullabies were likely experienced primarily at bedtime, and thus associated with security and tenderness rather than happiness or joy (Trainor et al., 1997). In addition, lullabies would be less familiar than the play songs that they hear repeatedly throughout the day (Bergeson \& Trehub, 2007), so lullabies might seem somewhat anomalous outside their usual context. Infants also respond differentially to these genres of singing, with play songs resulting in attention focused outward during play songs and self-focused during lullabies (Rock et al., 1999). In principle, such self-focus could prolong infant distress rather than alleviate it.

Play songs are effective in capturing infants' attention because of their variability in fundamental frequency (pitch), intensity (loudness), and rhythmicity (Corbeil et al., 2013; Trainor et al., 1997), in contrast to the lower pitch, slower 
tempo, and quieter sound levels of lullabies (Unyk et al., 1992). Such attention capture may play an important role in distracting infants from distressing events. Infants show long-term memory for melodies (Plantinga \& Trainor, 2005; Trainor, $\mathrm{Wu}, \&$ Tsang, 2004), so the familiarity of play songs may contribute to their impact. Additionally, mothers typically sing specific songs at the same pitch level on different occasions (Bergeson \& Trehub, 2002) and infants remember such performance features (Volkova, Trehub, \& Schellenberg, 2006), which would make maternal play songs even more familiar (Volkova et al., 2006). During caregivers' performances of songs, mothers and infants engage in responsive bidirectional exchanges resembling "call and response", where infant can interject sounds or actions (Trehub \& Trainor, 1998). These defining features of play songs may contribute to their efficacy in shifting infants' attention away from the previous stressor and re-engaging them in dyadic interaction.

In conclusion, the present experiment indicated that maternal play songs are more effective than maternal lullabies in ameliorating the distress of 10-month-old infants. Taken together with the findings of Experiment 1, the present study indicates that lively maternal singing, especially when it involves play songs, is an important caregiving tool. By successfully engaging infants, such singing seems to reduce their distress by a process of distraction. It remains to be determined whether play songs effectively "cure" the distress or if infant distress would reappear with the cessation of singing. 



\section{CHAPTER 4 : GENERAL DISCUSSION AND IMPLICATIONS}

\section{Overview}

The research in these two studies was aimed at ascertaining the effectiveness of maternal singing and speech in regulating the emotions of distressed 10-montholds. In Experiment 1, maternal singing was more effective than maternal speech in ameliorating infant distress induced by the mother's still-face. Such singing was differentially effective in engaging infants' attention and reducing their arousal, particularly during the last phase of the reunion episode. By contrast, as the reunion episode with maternal speech progressed, infants' SC arousal rose beyond that observed during the still-face episode. It is notable that mothers used more gentle and affectionate forms of touch such as holding and stroking infants while speaking rather than when they were singing. They also used more rhythmic movements while singing than while talking. In general, maternal singing was differentially effective in reducing infants' arousal and engaging them in playful interactions that seemed to distract them from their distressed state.

In Experiment 2, maternal play songs were more effective than maternal lullabies in reducing distress induced by the still-face procedure. After 30 seconds into the reunion episode, SC levels were significantly lower during play songs than during lullabies. Soothing maternal lullabies were not ineffective, but they took much longer to alleviate the distress of 10-month old infants than did maternal play songs. 
Taken together, the results of the two experiments indicate that maternal performances of lively play songs not only capture and sustain infants' attention and intense engagement but also reduce infant distress. What is it about play songs that underlies their efficacy at attention capture and stress reduction? Perhaps the predictability of play song performances is critical in establishing their efficacy. Mothers in the present study had been instructed to sing songs that they normally sing to their infants. In general, mothers sing the same songs repeatedly to their infants (Trehub et al., 1997), and their repeated performances of play songs are highly stereotyped in pitch level and tempo (Bergeson \& Trehub, 2002). Maternal song performances are also characterized by high levels of temporal regularity and rhythmicity (Nakata \& Trehub, 2004; Rock et al., 1997). Because Western mothers sing play songs much more frequently than lullabies, especially to awake, alert infants (Trehub \& Trainor, 1998), it is likely that the play songs and their performance nuances were more familiar to infants than were the lullabies. Infants exhibit long-term memory for specific musical pieces (e.g., Plantinga \& Trainor, 2005) and for the performance features of specific songs (Volkova et al., 2006). Therefore, when tensions rise and infants become distressed, familiar tunes (found in play songs) may be more comforting than less familiar songs and genres of singing. Rhythmic aspects of music are also highly salient to infants (Hannon \& Trehub, 2005), so the rhythmic movements that accompanied mothers' performances of play songs may have made those performances all the more compelling. 


\section{Adults' Responses to Singing and Music}

The stress-reducing aspects of music are not limited to infants. There is general consensus that music can counteract acute stress in adults (Chafin, Roy, Gerin, \& Christenfeld, 2004; Davis \& Thaut, 1989). For instance, music therapy reduces pain (e.g., Khalfa, Roy, Rainville, Dalla Bella, \& Peretz, 2008) and stress in medical settings (e.g., Koelsch et al., 2011). Favourite pieces of music often induce strong emotional responses, including shivers down the spine, laughter, and tears (Sloboda, 1991). Adults commonly use music for emotional self-regulation including distraction from unwanted thoughts and promotion of positive emotions or desirable cognitive states (Saarikallio \& Erkkila, 2007; Saarikallio, 2010). For example, percussive music with fast tempo (van der Zwaag, Westerink, \& van den Broek, 2011) or music considered happy or frightening elevates SC levels and feelings of tension (Khalfa, Peretz, Blondin, \& Manon, 2002; Russo, Vempala, \& Sandstrom, 2013). By contrast, adults experience music with slow tempo as more relaxing than music with faster tempo (Bernardi, Porta, \& Sleight, 2005). In studies where stress has been induced in adults, classical music rated "peaceful" is more effective than other music in reducing adults' SC levels following the stressor (Sandstrom \& Russo, 2010).

Essentially, maternal lullabies with their slow tempo (Trehub et al., 1993; Unyk et al., 1992) and maternal play songs with their faster tempo and increased rhythmicity (Rock et al., 1999) qualify for consideration as low and high arousal music, respectively. However, these two genres of maternal singing seem to evoke 
divergent physiological responses in infants (i.e., increasing SC responses to soothing lullabies) than in adults (i.e., decreasing SC responses to peaceful music). Why might that be the case? Arousing maternal music is a common means of inducing infant pleasure and reducing infant stress just as peaceful or soothing music is a common means of self-soothing for adults. Both involve the use of highly familiar musical materials, and both would have a history of associations with favourable outcomes. Distraction is a common goal, whether for mothers attempting to reduce infant distress or for adults attempting to lower their own stress. Adults would also have the capacity to re-direct their thoughts in an emotionally appropriate manner, whereas infants rely heavily on their caregivers to do this in their first year of life. There are also age-related changes in mothers' use of soothing techniques, with vocal distraction used more frequently with older infants and vocal soothing more frequently with infants below 6 months of age (Craig et al., 1984). It is possible, indeed likely, that maternal play songs and lullabies would have different consequences for infants of different ages and cultural backgrounds.

\section{Infants' Recovery from Distress}

Clearly, maternal singing was more effective than maternal speech for managing infant stress, and play songs were more effective than lullabies. It is notable, however, that physiological and behavioural indices failed to return to levels observed during the play episode. Three factors may have contributed to this outcome. First, the FFSF paradigm was modified to suit the goals of the present study, with the traditional still-face episode shortened from 2 minutes (e.g., Jean \& 
Stack, 2009) to 20 seconds so that infants could be exposed to cycles of stress induction and reunion featuring speech or singing (Experiment 1), and maternal lullabies and play songs (Experiment 2). Although the shortened still-face episodes were arguably milder than longer still-face episodes, the repeated episodes of stress induction may have had cumulative effects, exacerbating stress levels and therefore reducing the potential effectiveness of maternal interventions. The reunion episodes, at 90 seconds, were also shorter than the 2- to 3- minute reunion episodes in other FFSF studies, which may not have allowed sufficient time for the maternal intervention to be fully effective. Indeed, extrapolations of the data suggested that infants' SC levels during maternal singing would have returned to pre-SF levels shortly after 90 seconds. It is also worth noting that most infants seemed to enjoy their interactions with mothers, but those who were capable of locomotion may have been affected more adversely by confinement in the high chair for extended periods. Their mother, despite returning to "normal" behaviour during the reunion episodes, was unable to rescue them from their confinement, perhaps adding to their frustration.

Second, although mothers in both experiments were permitted to engage in multimodal soothing behaviours in addition to vocalization, including touch and facial and body gestures, but were prohibited from picking up their infants. Carrying is probably the most common and most effective intervention for distressed infants (e.g., Wolff, 1987). The opportunity to pick infants up, along with other interventions, would have reinforced the soothing and distracting aspects of 
maternal behaviour. Allowing mothers complete freedom of interaction with the exception for type of vocalization is an interesting future direction for research, but it poses numerous logistical problems such as keeping mother and infant within camera range, and measuring $\mathrm{SC}$ levels in moving infants.

Lastly, from the perspective of the infants as well as mothers, mothers were responsible for triggering the distress. The mother removed the infant's toys, then ceased interacting with her infant, only later attempting to mend the interaction. In other words, mothers provided mixed signals about their intentions, which may have complicated infants' recovery from distress.

Notwithstanding the above caveats, the present studies were the first to address questions about the specific effects of maternal speech and two forms of singing (play songs, lullabies) on the amelioration of infant distress. Undoubtedly, more research is needed to assess the effect of these maternal strategies on the time course of 10-month-olds' recovery from distress. It is equally important to explore similarities and differences in recovery from stress for infants of different age and cultural background, the different forms of stress induction (e.g., mother's departure, a stranger's arrival), as well as the course of recovery from such distress would also be of interest. Exploring these factors would highlight the development of infants' abilities in regulating their own distress and emotions across different situations and the influence of different cultures and upbringing. 


\section{Maternal Sensitivity and Infants' Self-Regulation}

Maternal sensitivity is considered critical for regulating infant emotion, especially in situations of distress (Conradt \& Ablow, 2010). Infants require optimal amount of emotion regulation where over- and under-stimulation are associated with infant's negative emotionality and disengagement (Stifter \& Moyer, 1991). Mothers' interpretation of and responsiveness to infants' "unspoken" signals (e.g., facial expression, gaze aversion) contribute to moments of attunement and synchrony (Haley \& Stansbury, 2003), which has long-term consequences for infants' development of effective self-regulation strategies (Calkins et al., 1999). In fact, infants of mothers who demonstrate sensitive caregiving are more likely to adopt effective self-regulation strategies when distressed (e.g., gaze aversion) than more immature strategies (e.g., thumb-sucking) (Gable \& Isabella, 1992; Stifter \& Moyer, 1991; Tronick, Ricks, \& Cohn, 1982).

It is difficult to know whether mothers in the present studies were optimally sensitive to their infants' signals. Mothers generally exhibited positive and neutral facial expressions as they spoke and sang, but were more likely to utilize more empathetic and compassionate forms of touch to re-engage with their infants when they spoke. Although infants' self-regulation strategies were not examined in these studies, the findings suggest that as infants became fussy, they were more likely to divert their attention and gaze away from their mother. That said, it would be interesting in future studies to examine the effects of maternal sensitivity and infants' self-regulation strategies in these conditions. 


\section{Prosodic Features of Maternal Vocalizations}

As mentioned in the outset, "motherease" has characterizations that give meaning and insight into the mother's emotional state (Trehub et al., 1997), and make these utterances highly melodic (Fernald, 1989, 1991). The prosodic features such as mothers' exaggerated intonations, vowel lengthening, longer pauses and variations in pitch, not only enhance the acoustic salience of speech but also conveys affective information that effectively attracts the infants' attention (See Fernald \& Mazzie, 1991). As previously discussed, the mother-infant interactions are multimodal involving both vocal and facial expressions. The literature suggests that mothers' positive emotions such as maintaining a smile or an exaggerated happy expression alters the shape of their vocal tract and voice quality (Laver, 1980) and results in an increase in their pitch levels which infants prefer (Trehub et al., 1993). In our study, mothers smiled equally in both speaking and singing conditions which made both interactions equally inviting. Interestingly, mothers were more "emotionally charged" and displayed greater exaggerated expressions while singing than when speaking. While the affective information in maternal vocalizations and facial expressions are often coordinated, it is not clear what role mothers' prosodic communication played in our studies and it would be an important direction for future research to investigate this factor.

\section{Expressions of Maternal Joy}

One might argue that maternal singing was more effective in modulating infants' arousal because of its greater novelty as compared to maternal speech, 
which is ubiquitous. As discussed previously, in stressful circumstances, familiar material found in mother's singing (particularly play songs) provides greater reassurance for the infant, and effectively shifts their attention away from the stressful event. In both studies, mothers were free to adjust various aspects of their vocal and non-vocal expressiveness. The observational data indicated greater evidence of joyful and exuberant expressiveness during play songs than during speech or lullabies. Happy or joyful speech and singing reliably attract and maintain the attention of Western infants (Corbeil et al., 2013; Singh, Morgan, \& Best, 2002). In fact, joyful ID vocalizations are more effective than less joyful ID vocalizations whether they involve speech or singing (Corbeil et al., 2013). The consequences for infants may arise from a process of emotional contagion between mother and infant (Holodynski \& Friedlmeier, 2010). Maternal behaviour provides a model for infant behaviour, with positive maternal expressiveness promoting positive infant expressiveness (Holondynski \& Friedlmeier, 2006). In Experiments 1 and 2, infants may have become "infected" by their mother's exaggerated facial expressions, rhythmic vocalizations and movements, as well as happy vocal tone that were part of her multimodal play song performances.

Similarly, the data can be supported by the social bio-feedback model of affect regulation (e.g., Fonagy \& Target, 1997; Jaffe, Beebe, Feldstein, Crown, \& Jasnow, 2002), suggesting that maternal facial and vocal mirroring of affective behaviour is central to emotion regulation during the first year of life. Specifically, the model by Fonagy and Target (1997) posits that sensitive mothers who can optimally regulate 
their infants' emotion are first able to join in their infants' experience of the negative emotion (e.g., sadness) and subsequently provide emotion regulation by showing an incompatible emotion (e.g., playfulness). This requires for mothers to not only understand and relate to their infants' mental and emotional state, but contingently mirror the emotional expressions of their infant before providing regulatory assistance. Previous research supports this finding where sensitive caregivers are more likely to reflect their infants' expressions of interest and happiness with increased (and often exaggerated) emotions of interest and happiness during the play and reunion episodes of the FFSF paradigm (Malatesta, Culver, Tesman, \& Shepard, 1989). While the first Experiment did not examine mother-infant emotional contingency and affective synchronization, it is possible that in the speech condition mothers are empathetically mirroring infants' negative behaviours and are somewhat successful in decreasing infants' negative behavioural responses (by the last reunion phase). In the singing condition on the other hand, mothers are perhaps mirroring infants' emotional expressions (as evidenced by their lack of exaggerated expressions in reunion I) and are then more successful in providing infants with a form of regulatory assistance through distraction and rhythmic playfulness of their singing (particularly play songs). In sum, the interplay between parental affect mirroring as well as infant motor mimicry leads to a synchronization of affective expressions which may further explain the effectiveness of playful singing in regulating infants' emotions. 


\section{Cross-Cultural Factors}

The less favourable impact of lullabies in regulating infants' emotion may be related, in part, to experiential factors. In a study that asked mothers to select songs of their choice when singing to infants, North American mothers sang playful and stimulating songs, in contrast to East Indian (Hindi-speaking) mothers, who sang slow, soothing songs (Trehub et al., 1993). In India, mothers typically remain with their infants throughout the day and night, lulling frequently to keep them content or help them fall asleep. By contrast, North American mothers sing lullabies relatively infrequently (Trehub et al., 1993, 1997). Mothers in Experiment 1 were provided guidance about when to sing but not about what to sing, and the majority of mothers sang play songs. With such a choice, mothers in many other cultures would choose to sing lullabies. It would be of considerable interest to ascertain whether maternal lullabies in those cultures would have consequences comparable consequences for distressed infants as did maternal play songs in the present study.

\section{Broader Implications of the Findings}

Mother-Infant Synchrony and Repairing Broken Interactions

Caregivers play a vital role in the regulation of emotions in infants and toddlers (Tronick, 1989). As noted, mother-infant interactions are not always congruent, often oscillating between matched (synchronous) and mismatched (asynchronous) states (DiCorcia \& Tronick, 2011). Aside from achieving synchrony in mother-infant interactions, a major component of emotional regulation is the 
ability to repair and recover from incongruities. The efficacy of maternal singing in modulating infants' arousal suggests that such singing can transform mother-infant asynchrony into more synchronous states. ID songs are highly predictable not only because of their familiarity but also because of their temporal regularity and rhythmicity (Bergeson \& Trehub, 2002; Corbeil et al., 2013; Trainor, 1996). The rhythmicity of play songs makes them especially engaging and effective for distracting infants from stressors and alleviating their distress. Maternal singing enables distal communication when physical proximity or visual regard is precluded (e.g., rear-facing car seat). These factors make play songs an effective means of preventing asynchronous interactions, restoring synchrony, and regulating infant emotion.

\section{Maternal Vocal Interactions in Clinical Settings}

Maternal vocal interventions can be useful with atypical populations such as premature infants, who may spend weeks, even months, in a neonatal intensive care unit (NICU). These infants experience high stress levels in the NICU and, even after discharge, they are generally more fragile, irritable, and less rewarding social partners (Eckerman, Oehler, Hannan, \& Molitor, 1995; Goldberg, 1978). In the NICU, exposure to recorded maternal sounds has favourable effects on preterm infants' cardiorespiratory outcomes (Doheny, Hurwitz, Insoft, Ringer, \& Lahav, 2012) and weight gain (Zimmerman, Keunen, Norton, \& Lahav, 2013). Recorded music and live singing also have positive effects on a number of physiological indices (Cassidy \& Standley, 1995; Longhi \& Pickett, 2008; Lorch, Lorch, 
Diefendorf, \& Earl, 1994). To date, there has been little exploration of the effects of different song genres (e.g., lullabies, play songs) on this population. Preterm infants in the NICU experience dangerously high stress levels because of their fragile medical condition and undergoing various medical procedures as well as enduring chaotic and often unfamiliar auditory environments, so lullabies may be especially suitable as musical interventions. However, this question warrants further investigation.

Maternal depression (e.g., post-partum, substance abuse, or trauma history) is another clinical population that may greatly benefit from singing and musical interventions to regulate their infants' emotions. Generally, depressed mothers are more likely to have flat affect and demonstrate inconsistent and disengaged patterns of social interaction (Campbell, 2010; Feldman \& Eidelman, 2007; Field et al., 2009). These behaviours can particularly impact infants' development and predispose children to other developmental issues later on (Feldman \& Eidelman, 2007; Lovejoy, Graczyk, O’Hare, \& Neuman, 2000). Depressed mothers demonstrate a slower ability to detect and respond to micro-level shifts in their infants' facial expressions (Feldman, 2007c) and tend to respond with greater hostility and intrusive behaviours towards infants' negative behaviours and crying (Field, 1992; Lovejoy et al., 2000). Their speeches often lack rhythmicity and are less focused on the infants' activities (Murray, Kempton, Woolgar, \& Hooper, 1993), and their interactions with their infants involves lower levels of contingency and less covocalizations during mutual gazing (Feldman, Granat, \& Gilboa-Schechtman, 
2005). According to a proposed theory by Field and her colleagues, when the parent suddenly becomes unavailable (as emulated in the still-face episode of FFSF paradigm), the dyad's social interaction is lost and the infant's emotions become dysregulated, resulting in changes to the infant's behaviour, physical state and affect (Field, 1994; Striano, 2004). In both Experiment 1 and 2, infants' increased negative emotional expressions and physiological stress were evident when mothers suddenly became unavailable and unresponsive in the still-face episode. While the present studies examined emotion regulation in typical mother-infant dyads, the use of maternal singing (particularly play songs) can provide a suitable and familiar way for depressed mothers to restore a level of joint rhythmical engagement and more importantly provide emotion regulation to fussing infants.

In general, mothers use vocal and tactile soothing strategies more frequently with younger infants and distracting vocal and non-vocal distal behaviours with older infants (Craig et al., 1984; Kopp, 1989). Whereas lullabies are used more commonly in early infancy for comforting infants, play songs provide stimulation and information that is more suitable for older infants (Trehub \& Trainor, 1998). The typically developing infants in the present study may have responded more favourably to the highly rhythmic play songs, but lullabies may be more suitable for much younger and more fragile premature infants. Overall, in the case of both depressed mothers and premature infants, singing may provide a suitable means for mothers to reconnect with their infants. 


\section{Limitations}

The present study attempted to capture the consequences of maternal speech and two genres of singing on distressed infants, but differences in maternal behaviour went well beyond the vocal domain. Not surprisingly, maternal non-vocal behaviour was coordinated with maternal vocal behaviour. As a result, it was impossible to pinpoint the features or combinations of features-acoustic, visual, tactile, and other-that were responsible for differential changes in infant arousal and behaviour across contexts. Moreover, measurement of mothers' own physiological arousal and synchronization with their infant will provide further insight to the emotion regulation literature. Parametric studies might succeed in isolating the critical factors, but they would have the limitation of compromising the natural quality of maternal interactions.

Maternal speech and singing interactions with infants occur commonly at home and elsewhere, which made the reunion episodes in Experiment 1 relatively natural for mothers and infants. Obviously, the induction of stress was unnatural, but it was preferable to waiting for spontaneous episodes of distress, which would undoubtedly differ in their nature and severity across infants. Imposing a particular genre of singing, regardless of mothers' use of those genres, may have had unforeseen consequences for infants. The lesser efficacy of lullabies may be attributable, in part, to their lesser familiarity for infants and mothers. If the lullabies were relatively unfamiliar to infants, they might provide less comfort than otherwise. If they were relatively unfamiliar to mothers, this might be reflected in 
maternal performances that were less expressive than they might be otherwise. This problem is one that could be rectified in future research by examining the prosodic features of maternal communications to their infants. However, given Western mothers' propensity to sing play songs rather than lullabies (Trehub \& Trainor, 1998; Trehub et al., 1993), it may be difficult to recruit a sample of mothers who sing lullabies as frequently as other mothers who sing play songs.

Finally, infant temperament may affect the kinds of maternal interactions, playful or soothing, that alleviate infant distress, and temperament was not assessed in the present study. For example, infants who are quiet, reserved, or wary may be more responsive to lullabies than to play songs, in contrast to more vivacious infants who might be more responsive to lively maternal interventions such as performances of play songs.

\section{Summary}

The present study revealed that maternal singing was more effective than maternal speech in regulating the behavioural and physiological arousal of 10month-old infants. The rhythmic sound of maternal singing accompanied by rhythmic movement and touch and exaggerated facial expressions yielded a multimodal stimulus that effectively captured the attention and ameliorated the distress of infants. Maternal play songs led to lower skin-conductance levels as well as greater sustained attention and contentment than maternal speech or maternal lullabies. These results suggest that lively maternal singing supports infants' emotional well-being and prolongs infant contentment by ameliorating distress 
within a dynamic infant-caregiver exchange. Such singing also supports caregivers' well-being by providing them with an effective and easy tool for regulating the emotions of their infant. 



\section{APPENDICES}

Appendix 1: Child Pre-Observations Questionnaire - Study 1

Study Name:

Researcher:

Participant Number:

Date:

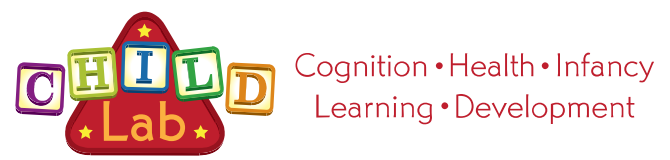

SMARI

\section{PRE-OBSERVATION QUESTIONNAIRE}

Welcome to the CHILD Lab! Before we begin our session, we ask that you complete this simple questionnaire regarding your child's early development. We will use your responses to help us to better answer our research questions. Please answer the following as accurately as possible. You are not obligated to answer any of the questions you do not feel comfortable with and may stop participating at any time without penalty. All questionnaire responses will be entered into a secure database and will be kept private and confidential. If you have any questions, please contact Niusha Ghazban (416-370-5000 ext. 4859 or nghazban@ryerson.ca), the researcher listed on the copy of the consent form you were given to take home.

\section{SECTION I: PERSONAL INFORMATION}

Address:

Telephone:

I would like to receive your newsletter featuring updates about the lab and results from previous studies Please contact me if my son/daughter is eligible to participate in future studies

May we contact you by email? $\square$ Yes $\square$ No Email address:

How did you hear about our lab?

$\square$ Brochure / Poster $\square$ Website $\square$ Friend $\square$ Resource Centre:

\section{SECTION II: INFORMATION ABOUT YOUR INFANT}

Gender: $\square$ Male $\square$ Female

Date of Birth (dd/mm/yy):

Expected Date of Birth:

Were there any complications during pregnancy or delivery?

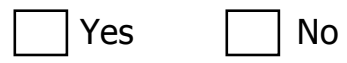

If yes, can you note the nature of complication?
Ethnicity:
South Asian
$\square$ Black
Caucasian
Filipino
Latin American
$\square$ Chinese
Aboriginal
Other:

Birth Order:

Age of siblings:

Does your child have any hearing impairments and do you have any concerns or general comments regarding your child's development? 


\section{PRE-OBSERVATION QUESTIONNAIRE}

Welcome to the CHILD Lab! Before we begin our session, we ask that you complete this simple questionnaire regarding your child's early development. We will use your responses to help us to better answer our research questions. Please answer the following as accurately as possible. You are not obligated to answer any of the questions you do not feel comfortable with and may stop participating at any time without penalty. All questionnaire responses will be entered into a secure database and will be kept private and confidential. If you have any questions, please contact Niusha Ghazban (416-370-5000 ext. 4859 or nghazban@ryerson.ca), the researcher listed on the copy of the consent form you were given to take home.

\section{SECTION I: PERSONAL INFORMATION}

Address:

Telephone:

I would like to receive your newsletter featuring updates about the lab and results from previous studies

Please contact me if my son/daughter is eligible to participate in future studies

May we contact you by email? $\square$ Yes $\square$ No Email address:

How did you hear about our lab?

$\square$ Brochure / Poster $\square$ Website $\square$ Friend $\square$ Resource Centre:

Other:

SECTION II: INFORMATION ABOUT YOUR INFANT

Gender: $\square$ Male $\square$ Female

Name:

Date of Birth (dd/mm/yy):

Expected Date of Birth:

Were there any complications during pregnancy or delivery? $\square$ Yes $\square$ No If yes, can you note the nature of complication?
Ethnicity:

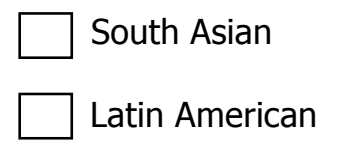
$\square$ Black
$\square$ Caucasian
Filipino
Chinese
Aboriginal
Other:

Birth Order:

Age of siblings: 
SECTION III: MUSICAL EXPOSURE OF YOUR SON/DAUGHTER

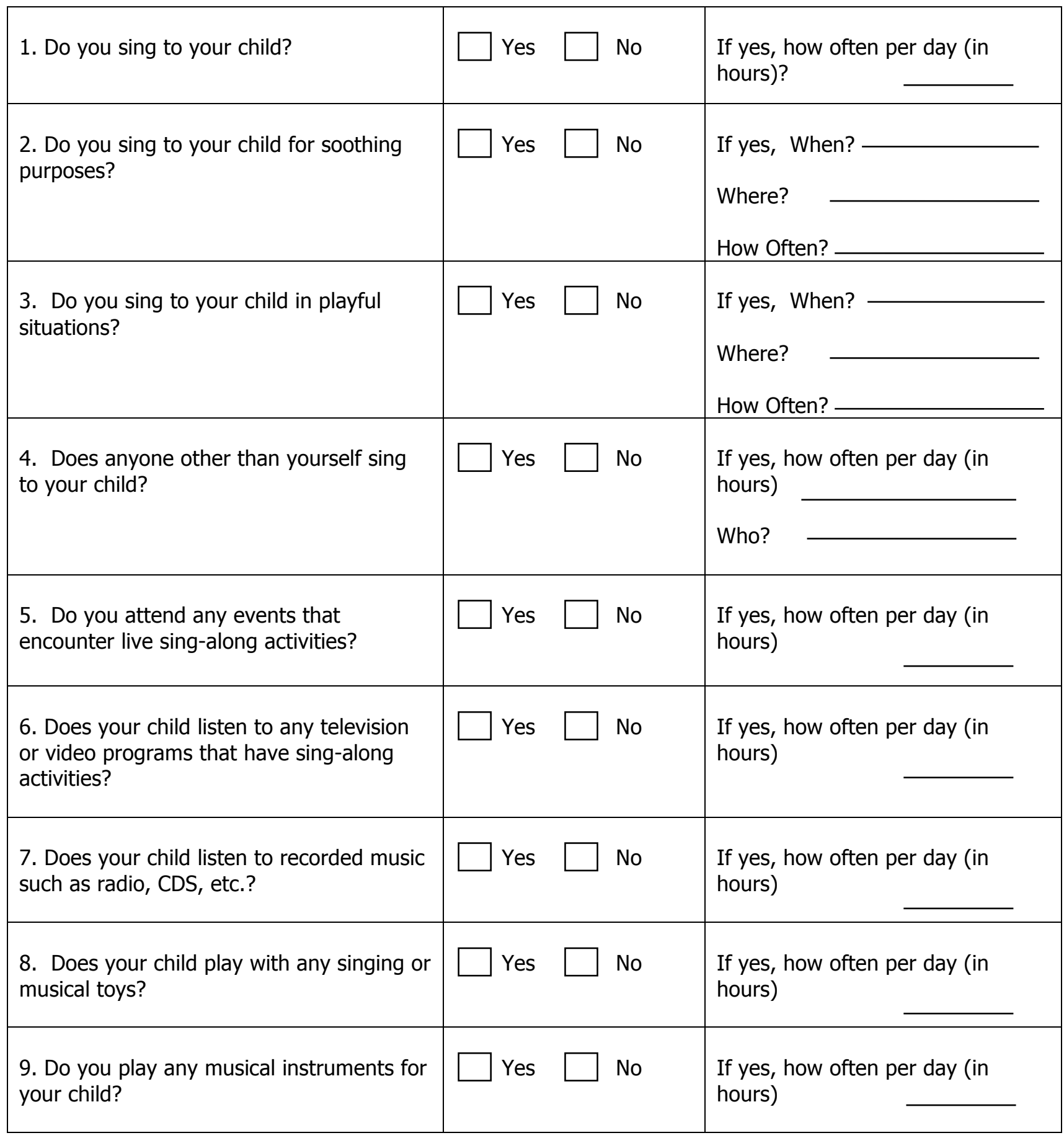

Does your child have any hearing impairments and do you have any concerns or general comments regarding your child's development?

Thank you! The next session will begin shortly... 



\section{REFERENCES}

Adamson, L. B., \& Frick, J. E. (2003). The still face: A history of a shared experimental paradigm. Infancy, 4, 451-473.

Andrews, A. J., Nespoli, G. A., \& Russo, F. A. (2012). FeatureFinder (Version 2.4.1). Toronto: SMART Laboratory, Department of Psychology, Ryerson University. Retrieved from www.featurefinder.ca

Bazhenova, O. V, Stroganova, T. A., Doussard-Roosevelt, J. A., Posikera, I. A., \& Porges, S. W. (2007). Physiological responses of 5-month-old infants to smiling and blank faces. International Journal of Psychophysiology, 63, 64-76.

Bergeson, T. R., \& Trehub, S. E. (2007). Signature tunes in mothers' speech to infants. Infant Behavior and Development, 30, 648-654.

Bernardi, L., Porta, C., \& Sleight, P. (2005). Cardiovascular, cerebrovascular, and respiratory changes induced by different types of music in musicians and nonmusicians: the importance of silence. Heart, 92, 445-452.

Brandt, A., Gebrian, M., \& Slevc, L. R. (2012). Music and early language acquisition. Frontiers in psychology, 3, 327.

Brazelton, T. B., Koslowski, B., \& Main, M. (1974). The origins of recipriocity: The early mother-infant interaction. In M. Lewis \& L. A. Rosenblum (Eds.), The effects of the infant on its caregiver (pp. 49-76). New York: Wiley.

Calkins, S. D., Gill, K. L., Johnson, M. C., \& Smith, C. L. (1999). Emotional reactivity and emotional regulation strategies as predictors of social behavior with peers during toddlerhood. Social Development, 8, 310-334. 
Calkins, S. D., \& Keane, S. P. (2004). Cardac vagal regulation across the preschool period: Stability, continuity, and implications for childhood adjustment. Developmental Psychobiology2, 45, 101-112.

Campos, J. J., \& Stenberg, C. (1981). Perception, appraisal, and emotion: The onset of social referencing. In M. Lamb \& L. Sherrod (Eds.), Infant social cognition (pp. 604-616). Hillsdale, NJ: Erlbaum.

Campos, R. G. (1994). Rocking and pacifiers: two comforting interventions for heelstick pain. Research in nursing health (Vol. 17, pp. 321-331).

Cassidy, J. W., \& Standley, J. M. (1995). The effect of music listening on physiological responses of premature infants in the NICU. Journal of Music Therapy, 32, 208-227.

Chafin, S., Roy, M., Gerin, W., \& Christenfeld, N. (2004). Music can facilitate blood pressure recovery from stress. British Journal of Health Psychology, 9, 393403.

Cohn, J. F., \& Tronick, E. Z. (1988). Mother-infant interaction: Influence is bidirectional and unrelated to periodic cycles in either partner's behavior. Developmental Psychology, 24, 386-392.

Conradt, E., \& Ablow, J. (2010). Infant physiological response to the still-face paradigm: Contributions of maternal sensitivity and infants' early regulatory behavior. Infant Behavior and Development, 33, 251-265.

Cooper, R. P., \& Aslin, R. N. (1990). Preference for Infant-Directed Speech in the First Month after Birth. Child Development, 61, 1584. 
Corbeil, M., Trehub, S. E., \& Peretz, I. (2013). Speech vs. singing: Infants choose happier sounds. Frontiers in psychology, 4, 1-12.

Craig, K. D., McMahon, R. S., Morison, J. D., \& Zaskow, C. (1984). Developmental changes in infant pain expression during immunization injections. Social Science and Medicine, 19, 1331-1337.

Davis, W. B., \& Thaut, M. H. (1989). The influence of preferred relaxing music on measures of state anxiety, relaxation, and physiological responses. Journal of Music Therapy, 26, 168-187.

De l'Etoile, S. K. (2006). Infant behavioral responses to infant-directed singing and other maternal interactions. Infant Behavior and Development, 29, 456-470.

Denham, S., Blair, K., DeMulder, E., Levitas, J., Sawyer, K., \& Auerbach-Major, S. (2003). Preschool emotional competence: Pathway to social competence. Child Development, 74, 238-256.

DiCorcia, J. A., \& Tronick, E. Z. (2011). Quotidian resilience: exploring mechanisms that drive resilience from a perspective of everyday stress and coping. Neuroscience and biobehavioral reviews, 35, 1593-602.

Doheny, L., Hurwitz, S., Insoft, R., Ringer, S., \& Lahav, A. (2012). Exposure to biological maternal sounds improves cardiorespiratory regulation in extremely preterm infants. The journal of maternal-fetal \& neonatal medicine, 25, 15911594.

Eckerman, C. O., Oehler, J. M., Hannan, T. E., \& Molitor, A. (1995). The development prior to term age of very prematurely born newborns' 
responsiveness in an en face exchange. Infant Behavior and Development, 18, $283-297$.

Eisenberg, N., Cumberland, A., \& Spinrad, T. L. (1998). Parental socialization of emotion. Psychological Inquiry, 9, 241-273.

Eisenberg, N., Fabes, R. A., \& Murphy, B. C. (1996). Parents' reactions to children's negative emotions: Relations to children's social competence and comforting behavior. Child Development, 67, 2227-2247.

Eisenberg, N., Fabes, R. A., Murphy, B., Karbon, M., Smith, M., \& Maszk, P. (1996). The relations of children's dispositional empathy-related responding to their emotionality, regulation, and social functioning. Developmental Psychology, 32, $195-209$.

Eriksson, M., Storm, H., Fremming, A., \& Schollin, J. (2008). Skin conductance compared to a combined behavioural and physiological pain measure in newborn infants. Acta Paediatrica, 97, 27-30.

Feldman, R. (2006). From biological rhythms to social rhythms: Physiological precursors of mother-infant synchrony. Developmental Psychology, 42, 175-188.

Feldman, R. (2007a). On the origins of background emotions: From affect synchrony to symbolic expression. Emotion, 7, 601-611.

Feldman, R. (2007b). Parent-infant synchrony: Biological foundations and developmental outcomes. Current Directions in Psychological Science, 16, 340345 . 
Feldman, R., \& Eidelman, A. I. (2007). Maternal postpartum behavior and the emergence of infant-mother and infant-father synchrony in preterm and fullterm infants: The role of neonatal vagal tone. Developmental Psychobiology, 49, 290-302.

Feldman, R., Masalha, S., \& Alony, D. (2006). Microregulatory patterns of familly interactions: Cultural pathways to toddlers; self-regulation. Journal of Family Psychology, 20, 614-623.

Feldman, R., Singer, M., \& Zagoory, O. (2010). Touch attenuates infants' physiological reactivity to stress. Developmental Science, 13, 271-278.

Fernald, A. (1985). Four-month-old infants prefer to lsiten to motherese. Infant Behavior and Development, 8 .

Fernald, A. (1989). Intonation and Communicative Intent in Mothers' Speech to Infants: Is the Melody the Message? Child Development, 60, 1497.

Fernald, A. (1991). Prosody in speech in children: Prelinguistic and linguistic functions. Child Development, 8, 43-80.

Fernald, A. (1993). Approval and disapproval: infant responsiveness to vocal affect in familiar and unfamiliar languages. Child development, 64, 657-74.

Fernald, A., \& Mazzie, C. (1991). Prosody and focus in speech to infants and adults. Developmental Psychology, 27, 209-221.

Fernald, A., \& Simon, T. (1984). Expanded intonation contours in mothers' speech to newborns. Developmental Psychology, 20, 104-113. 
Fogel, A., Diamond, G. R., Langhorst, B. H., \& Demos, V. (1982). Affective and cognitive aspects of the 2-month-old's participation in face-to-face interaction with the mother. In Edward Z Tronick (Ed.), Social interchange in infancy: Affect, cognition, and communication (pp. 37-57). Baltimore: University Park Press.

Fonagy, P., \& Target, M. (1997). Attachment and reflective function: Their role in self-organization. 1Development and Psychopathology, 9, 679-700.

Gable, S., \& Isabella, R. A. (1992). Maternal contributions to infant regulation of arousal. Infant Behaviour and Development, 15, 95-107.

Garnica, O. (1977). Some prosodic and paralinguistic features of speech to young children. In C. E. Snow \& C. A. Ferguson (Eds.), Talking to children: Language input and acquisition. Cambridge, England: Cambridge University Press.

Gianino, A., \& Tronick, E. Z. (1986). The mutual regulation model: The infant's self and interactive regulation and coping and defensive capacities. In T. Field. \& P. McCabe. (Eds.), Stress and coping (pp. 47-68). Hillsdale, NJ: Erlbaum.

Gladman, G., \& Chiswick, M. L. (1990). Skin conductance and arousal in the newborn. Archives of Disease in Childhood, 65, 1063-1066.

Goldberg, S. (1978). Prematurity: Effects on parent- infant interactions. Pediatric Psychology, 3, 137-144.

Grieser, D. L., \& Kuhl, P. K. (1988). Maternal speech to infants in a tonal language: Support for universal prosodic features in motherese. Developmental Psychology, 24, 14-20. 
Gunnar, M. R., Mangelsdorf, S. C., Larson, M., \& Hertsgaard, L. (1989).

Attachment, temperament, and adrenocortical activity in infancy: A study of psychoendocrine regulation. Developmental Psychology, 25, 355-363.

Gusella, J. L., Muir, D., \& Tronick, E. Z. (1988). The effect of manipulating maternal behavior during an interaction on three-and six-month-olds' affect and attention. Child Development, 59, 1112.

Haley, D. W., \& Stansbury, K. (2003). Infant stress and parent responsiveness: Regulation of physiology and behavior during still-face and reunion. Child Development, 74, 1534-1546.

Ham, J., \& Tronick, E. Z. (2006). Infant resilience to the stress of the still-face: Infant and maternal psychophysiology are related. Resilience in Children, 1094, 297-302.

Ham, J., \& Tronick, E. Z. (2008). A procedure for the measurement of infant skin conductance and its initial validation using clap induced startle. Developmental Psychobiology, 50, 626-631.

Ham, J., \& Tronick, E. Z. (2009). Relational psychophysiology: Lessons from mother-infant physiology research on dyadically expanded states of consciousness. Psychotherapy Research, 19, 619-632.

Hannon, E. E., \& Trehub, S. E. (2005). Metrical categories in infancy and adulthood. Psychological Science, 16, 48-55.

Harman, C., Rothbart, M., \& Posner, M. (1997). Distress and attention interactions in early infancy. Motivation and Emotion, 21, 27-43. 
Harrison, D., Boyce, S., Loughnan, P., Dargaville, P., Storm, H., \& Johnston, L. (2006). Skin conductance as a measure of pain and stress in hospitalised infants. Early Human Development, 82, 603-608.

Hernes, K. G., Morkrid, L., Fremming, A., Odegarden, S., Martinsen, O. G., \& Storm, H. (2002). Skin conductance changes during the first year of life in fullterm infants. Pediatric Research2, 52, 837-843.

Holodynski, M., \& Friedlmeier, W. (2010). Development of Emotions and Emotion Regulation (Vol. 2010, p. 265). Springer.

Jaffe, J., Beebe, B., Feldstein, S., Crown, C. L., \& Jasnow, M. D. (2002). Rhythms of dialogues in infancy. Monographs of the Society for Research in Child Development, 66.

Jahromi, L. B., Putnam, S. P., \& Stifter, C. a. (2004). Maternal regulation of infant reactivity from 2 to 6 months. Developmental psychology, 40, 477-87.

Jean, A. D. L., \& Stack, D. M. (2009). Functions of maternal touch and infants' affect during face-to-face interactions: New directions for the still-face. Infant Behavior and Development, 32, 123-128.

Jean, A. D. L., \& Stack, D. M. (2012). Full-term and very-low-birth-weight preterm infants' self-regulating behaviors during a Still-Face interaction: Influences of maternal touch. Infant Behavior and Development, 35, 779-791.

Jean, A. D. L., Stack, D. M., \& Fogel, A. (2009). A longitudinal investigation of maternal touching across the first six months of life: Age and context effect. Infant Behavior \& Development, 32, 342-349. 
Karraker, K. H., \& Lake, M. A. (1991). Normative stress and coping processes in infancy. In E. M. Cummings, A. L. Greene, \& K. H. Karraker (Eds.), Life-span developmental psychology: Perspectives on stress and coping (pp. 85-108). Hillsdale, NJ: Erlbaum.

Khalfa, S., Peretz, I., Blondin, J. P., \& Manon, R. (2002). Event-related skin conductance responses to musical emotions in humans. Neuroscience Letters, $328,145-149$.

Khalfa, S., Roy, M., Rainville, P., Dalla Bella, S., \& Peretz, I. (2008). Role of tempo entrainment in psychophysiological differentiation of happy and sad music? International Journal of Psychophysiology, 68, 17-26.

Koelsch, S., Fuermetz, J., Sack, U., Bauer, K., Hohenadel, M., Wiegel, M., ... Heinke, W. (2011). Effects of Music Listening on Cortisol Levels and Propofol Consumption during Spinal Anesthesia. Frontiers in psychology, 2, 58.

Kopp, C. B. (1989). Regulation of distress and negative emotions: A developmental view. Developmental Psychology, 25, 343-354.

Kuchuk, A., Vibbert, M., \& Bornstein, M. H. (1986). The perception of smiling and its experiential correlates in three-month-old infants. Child development, 57, 1054-61.

Lamb, M. E., Morrison, D. C., \& Malkin, C. M. (1987). The development of infant social expectations in face-to-face interaction: A longitudinal study. MerrillPalmer Quarterly- Journal of Developmental Psychology, 33, 241-254. 
Laver, J. (1980). The phonetic description of voice quality. Cambridge, England: Cambridge University Press.

Lewis, M., \& Ramsay, D. (1999). Effect of maternal soothing on infant stress response. Child development, 70, 11-20.

Longhi, E., \& Pickett, N. (2008). Music and well-being in long-term hospitalized children. Psychology of Music, 36, 247-256.

Lorch, C. A., Lorch, V., Diefendorf, A. O., \& Earl, P. W. (1994). Effect of stimulative and sedative music on systolic blood pressure, heart rate, and respirator rate in premature infants. Journal of Music Therapy, 31, 105-118.

Malatesta, C. Z., Culver, C., Tesman, J. R., \& Shepard, B. (1989). The development of emotion expression during the first two years of life. Monographs of the Society for Research in Child Development, 54, (1-2).

Masataka, N. (1999). Preference for infant-directed singing in 2-day-old hearing infants of deaf parents. Developmental Psychology, 35, 1001-1005.

Maya, G., \& Gratier, M. (2003). Expressive timing and interactional synchrony between mothers and infants: Cultural similarities, cultural differences, and the immigration experience. Cognitive Development, 18, 533-554.

Mesman, J., van IJzendoorn, M. H., \& Bakermans-Kranenburg, M. J. (2009). The many faces of the Still-Face Paradigm: A review and meta-analysis. Developmental Review, 29, 120-162. 
Milligan, K. (2000). Attachement and Depression: Communication and Perception of Emotion through Song. Ontario Institute for Studies in Education of the University of Toronto.

Moore, G. A., \& Calkins, S. D. (2004). Infants' vagal regulation in the still-face paradigm is related to dyadic coordination of mother-infant interaction. Developmental Psychology, 40, 1068-1080.

Moore, G. A., Hill-Soderlund, A. L., Propper, C. B., Calkins, S. D., Mills-Koonce, W. R., \& Cox, M. J. (2009). Mother-infant vagal regulation in the Face-To-Face Still-Face paradigm is moderated by maternal sensitivity. Child Development, 80, 209-223.

Moszkowski, R. J., \& Stack, D. M. (2007). Infant touching behaviour during motherinfant face-to-face interactions. Infant and Child Development, 16, 307-319.

Moszkowski, R. J., Stack, D. M., \& Chiarella, S. S. (2009). Infant touch with gaze and affective behaviors during mother-infant still-face interactions: Cooccurrence and functions of touch. Infant Behavior and Development, 32, 392403.

Munsters, J., Wallström, L., Agren, J., Norsted, T., \& Sindelar, R. (2012). Skin conductance measurements as pain assessment in newborn infants born at 2227 weeks gestational age at different postnatal age. Early Human Development $2,88,21-26$. 
Murray, L., \& Trevarthen, C. (1985). Emotional regulation of interactions between two-month-olds and their mothers. In T. F. \& N. A. Fox (Ed.), Social perception in infants (Vol. 177-197). Norwood, NJ: Ablex Publishing.

Nakata, T., \& Trehub, S. E. (2004). Infants' responsiveness to maternal speech and singing. Infant Behavior and Development, 27, 455-464.

Papoušek, H. (1996). Musicality in infancy research: Biological and cultural origins of early musicality. In I. D. \& J. Sloboda (Ed.), Musical beginnings: Origins and development of musical competence (pp. 37-55). Oxford: Oxford University Press.

Papoušek, H., \& Papoušek, M. (1987). Intuitive parenting: A dialectic counterpart to the infant's integrative competence. In J. Osofsky (Ed.), Handbook of infant development (pp. 669-720). New York: Wiley.

Papoušek, M. (1994). Melodies in caregivers' speech: A species-specific guidance towards language. Early Development and Parenting, 3, 5-17.

Papoušek, M. (2007). Communication in early infancy: An arena of intersubjective learning. Infant Behavior \& Development, 30, 258-266.

Papoušek, M., Bornstein, M. H., Nuzzo, C., Papoušek, H., \& Symmes, D. (1990). Infant responses to prototypical melodic contours in parental speech. Infant Behavior and Development, 13, 539-545.

Papoušek, M., \& Papoušek, H. (1981). Musical elements in the infant's vocalization: Their significance for communication, cognition and creativity. In L. P. Lipsitt 
\& C. K. Rovee-Collier (Eds.), Advances in Infancy Research (pp. 163-224). Norwood, NJ: Ablex.

Papoušek, M., Papoušek, H., \& Bornstein, M. (1985). The naturalistic vocal environment of young infants: on the signifcance of homogenity and variability in parental speech. In T. M. Field \& N. Fox (Eds.), Social perception in infants (pp. 269-279). Norwood, NJ: Ablex.

Peláez-Nogueras, M., Gewirtz, J. L., Field, T., Cigales, M., Malphurs, J., Clasky, S., \& Sanchez, A. (1996). Infants' preference for touch stimulation in face-to-face interactions. Journal of Applied Developmental Psychology, 17, 199-213.

Plantinga, J., \& Trainor, L. J. (2005). Memory for melody: Infants use a relative pitch code. Cognition, 98, 1-11.

Rock, A. M., Trainor, L. J., \& Addison, T. L. (1999). Distinctive messages in infantdirected lullabies and play songs. Developmental psychology, 35, 527-34.

Rothbart, M. K., Ziaie, H., \& O'Boyle, C. G. (1992). Self-regulation and emotion in infancy. New Directions for Child Development, 55, 7-23.

Russo, F. A., Vempala, N. N., \& Sandstrom, G. M. (2013). Predicting musically induced emotions from physiological inputs: Linear and neural network models. Frontiers in Psychology, 4, 468.

Saarikallio, S. (2010). Music as emotional self-regulation throughout adulthood. Psychology of Music, 39, 307-327.

Saarikallio, S., \& Erkkila, J. (2007). The role of music in adolescents' mood regulation. Psychology of Music, 35, 88-109. 
Saarni, C., Campos, J. J., Camras, L., \& Witherington, D. (2008). Principles of emotion and emotional competence. In W. Damon \& R. Lerner (Eds.), Child and adolescent development: An advanced course. Hoboken, NJ: Wiley.

Sandstrom, G. M., \& Russo, F. A. (2010). Music hath charms: The effects of valence and arousal on the regulation of stress. Music and Medicine, 2, 137-143.

Schogler, B., \& Trevarthen, C. (2007). To sing and dance together: From infants to jazz. In S. Braten (Ed.), On being moved: From mirror neurons to empathy (pp. 281-302). Amsterdam: John Benjamins Publishing Company.

Shapiro, B., Fagen, J., Prigot, J., Carroll, M., \& Shalan, J. (1998). Infants' emotional and regulatory behaviors in response to violations of expectancies. Infant Behavior \& Development, 21, 299-313.

Shenfield, T., Trehub, S. E., \& Nakata, T. (2003). Maternal singing modulates infant arousal. Psychology of Music, 31, 365-375.

Singh, L., Morgan, J. L., \& Best, C. T. (2002). Infants' Listening Preferences: Babytalk or Happy Talk? Infancy, 3, 365-394.

Sloboda, J. A. (1991). Music structure and emotional response. Psychology of Music, $19,110-120$.

Stack, D. M., \& Arnold, S. L. (1998). Changes in mothers' touch and hand gestures influence infant behavior during face-to-face interchanges. Infant Behavior \& Development, 21, 451-468. 
Stack, D. M., \& Muir, D. W. (1990). Tactile stimulation as a component of social interchange: New interpretations for the still-face effect. British Journal of Developmental Psychology, 8, 131-145.

Stack, D. M., \& Muir, D. W. (1992). Adult tactile Stimulation during Face-to-Face Interactions Modulates Five-Month-Olds' Affect and Attention. Child Development, 63, 1509-1525.

Stern, D. N. (1974). Mother and infant at play: The dyadic interaction involving facial, vocal and gaze behaviours. In M. L. \& L. A. Rosenblum (Ed.), The effect of the infant on its caregiver (pp. 187-213). New York: Wiley.

Stern, D. N. (1985). The interpersonal world of the infant: A view from psychoanalysis and developmental psychology. New York: Basic Books.

Stern, D. N., Spieker, S., Barnett, R. K., \& MacKain, K. (1983). The prosody of maternal speech: infant age and context related changes. Journal of Child Language, 10, 1-15.

Stern, D. N., Spieker, S., \& MacKain, K. (1982). Intonation contours as signals in maternal speech to prelinguistic infants. Developmental Psychology, 18, 727735.

Stifter, C. A., \& Moyer, D. (1991). The regulation of positive affect: Gaze aversion activity during mother-infant interaction. Infant Behavior and Development, $14,111-123$. 
Stoller, S., \& Field, T. (1982). Alteration of mother and infant behavior and heart rate during a still-face perturbation of face-to-face interaction. In T. Field \& A. Fogel (Eds.), Emotion and early interaction (pp. 57-82). Lawrence Erlbaum.

Storm, H. (2001). Development of emotional sweating in preterms measured by skin conductance changes. Early Human Development, 62, 149-158.

Striano, T., \& Bertin, E. (2004). Contribution of facial and vocal cues in the still-face response of 4-month-old infants. Infant Behavior and Development, 27, 499508.

Ter Vrugt, D., \& Pederson, D. R. (1973). The effects of vertical rocking frequencies on the arousal level in two-month-old infants. Child development, 44, 205-9.

Thompson, R. A. (1994). Emotion regulation: A theme in search of definition. Monographs of the Society for Research in Child Development, 59, 25-52.

Thompson, R. A., Lewis, M. D., \& Calkins, S. D. (2008). Reassessing emotion regulation. Child Development Perspectives, 2, 124-131.

Toda, S., \& Fogel, A. (1993). Infant response to the still-face situation at 3 and 6 months. Developmental Psychology, 29, 532-538.

Trainor, L. J. (1996). Infant preferences for infant-directed versus non-infant directed playsongs and lullabies. Infant Behavior and Development, 19, 83-92.

Trainor, L. J., Clark, E. D., Huntley, A., \& Adams, B. A. (1997). The acoustic basis of preferences for infant-directed singing. Infant Behavior and Development, 20, $383-396$. 
Trainor, L. J., Wu, L., \& Tsang, C. D. (2004). Long-term memory for music: Infants remember tempo and timbre. Developmental Science, 7, 289-296.

Trainor, L. J., \& Zacharias, C. A. (1998). Infants prefer higher-pitched singing. Infant Behavior and Development, 21, 799-805.

Trehub, S. E. (2003). The developmental origins of musicality. Nature Neuroscience, 6, 669-673.

Trehub, S. E., Hannon, E. E., \& Schachner, A. (2010). Perspectives on music and affect in the early years. In P. N. Juslin \& J. A. Sloboda (Eds.), Handbook of music and emotion: Theory, research, applications (pp. 645-668). New York, NY: Oxford University Press.

Trehub, S. E., Hill, D. S., \& Kamenetsky, S. B. (1997). Parents' sung performances for infants. Canadian Jounral of Experimental Psychology, 51, 385-396.

Trehub, S. E., \& Nakata, T. (2002). Emotion and music in infancy. Musicae Scientiae, Special Is, 37-61.

Trehub, S. E., \& Trainor, L. J. (1998). Singing to infants: Lullabies and play songs. Advances in Infancy Research, 12, 43-77.

Trehub, S. E., Trainor, L. J., \& Unyk, A. M. (1993). Music and speech processing in the first year of life. Advances in child development and behavior, 02, 1-35.

Tronick, E Z. (1995). Touch in mother-infant interactions. In T. M. Field (Ed.), Touch in early development (pp. 53-65). Mahwah, NJ: Erlbaum.

Tronick, E Z. (2005). Why is connection with others so critical? The formation of dyadic states of consciousness and the expansion of individuals' states of 
consciousness: Coherence governed selection and the co-creation of meaning out of messy meaning making. In J. N. \& D. Muir (Ed.), Emotional development: Recent research advances (pp. 293-315). Oxford: Oxford University Press.

Tronick, E Z, Als, H., Adamson, L., Wise, S., \& Brazelton, T. B. (1978). The infant's response to entrapment between contradictory messages in face-to-face interaction. Journal of American Academy of Child Psychiatry, 17, 1-13.

Tronick, E Z, Ricks, M., \& Cohn, J. F. (1982). Maternal and infant affective exchange: Patterns of adaptation. In T. F. \& A. Fogel (Ed.), Emotion and early interaction (Vol. 83-100). Hillsdale, NJ: Lawrence Erlbaum.

Unyk, A. M., Trehub, S. E., Trainor, L. J., \& Schellenberg, E. G. (1992). Lullabies and Simplicity: A Cross-Cultural Perspective. Psychology of Music, 20, 15-28.

Van der Zwaag, M. D., Westerink, J. H. D. M., \& van den Broek, E. L. (2011). Emotional and psychophysiological responses to tempo, mode, and percussiveness. Musicae Scientiae, 15, 250-269.

Volkova, A., Trehub, S. E., \& Schellenberg, E. G. (2006). Infants' memory for musical performances. Developmental Science, 9, 583-589.

Walker-Andrews, A. S. (1986). Intermodal perception of expressive behaviors: Relation of eye and voice? Developmental Psychology, 22, 373-377.

Walker-Andrews, A. S. (1988). Infants' perception of the affordances of expressive behaviors. Advances in Infancy Research, 5, 173-221. 
Weinberg, M. K., \& Tronick, E. Z. (1994). Beyond the face: An empirical-study of infant affective configurations of facial, vocal, gestural, and regulatory behaviors. Child Development, 65, 1503-1515.

Weinberg, M. K., \& Tronick, E. Z. (1996). Infant affective reactions to the resumption of maternal interaction after the still-face. Child Development, 67, $905-914$.

Weinberg, M. K., Tronick, E. Z., Cohn, J. F., \& Olson, K. L. (1999). Gender differences in emotional expressivity and self-regulation during early infancy. Developmental Psychology, 35, 175-188.

Werker, J., \& McLeod, P. (1989). Infant preference for both male and female infantdirected talk: A developmental study of attentional affective responsiveness. Canadian Jounral of Experimental Psychology, 43, 230-246.

Wolff, P. H. (1987). The development of behavioral states and the expression of emotions in early infancy. Chicago: University of Chicago Press.

Zimmerman, E., Keunen, K., Norton, M., \& Lahav, A. (2013). Weight Gain Velocity in Very Low-Birth-Weight Infants: Effects of Exposure to Biological Maternal Sounds. American journal of perinatology. doi:10.1055/s-0033-1333669 